NBER WORKING PAPER SERIES

\title{
THE IMPACT OF THE FEDERAL PANDEMIC UNEMPLOYMENT COMPENSATION ON JOB SEARCH AND VACANCY CREATION
}

\author{
Ioana Marinescu \\ Daphne Skandalis \\ Daniel Zhao \\ Working Paper 28567 \\ http://www.nber.org/papers/w28567 \\ NATIONAL BUREAU OF ECONOMIC RESEARCH \\ 1050 Massachusetts Avenue \\ Cambridge, MA 02138 \\ March 2021
}

We would like to thank Hyeri Choi and Jie Guan for excellent research assistance. We would like to thank for their very helpful comments Steffen Altmann, Antoine Bertheau, Sydnee Caldwell, Nikolaj Harmon, Robert Mahlstedt, Pascal Noel, as well as the participants of the seminars in UCD Dublin, Harvard, Essex/Royal Holloway/Bristol. The views expressed herein are those of the authors and do not necessarily reflect the views of the National Bureau of Economic Research.

NBER working papers are circulated for discussion and comment purposes. They have not been peerreviewed or been subject to the review by the NBER Board of Directors that accompanies official NBER publications.

(C) 2021 by Ioana Marinescu, Daphne Skandalis, and Daniel Zhao. All rights reserved. Short sections of text, not to exceed two paragraphs, may be quoted without explicit permission provided that full credit, including $\odot$ notice, is given to the source. 
The Impact of the Federal Pandemic Unemployment Compensation on Job Search and Vacancy

Creation

Ioana Marinescu, Daphne Skandalis, and Daniel Zhao

NBER Working Paper No. 28567

March 2021

JEL No. J63,J64,J65

\begin{abstract}
During the COVID-19 pandemic, the Federal Pandemic Unemployment Compensation (FPUC) increased US unemployment benefits by $\$ 600$ a week. Theory predicts that FPUC will decrease job applications, and could decrease vacancy creation. We estimate the effect of FPUC on job applications and vacancy creation week by week, from March to July 2020, using granular data from the online jobs platform Glassdoor. We exploit variation in the proportional increase in benefits across local labor markets. To isolate the effect of FPUC, we flexibly allow for different trends in local labor markets differentially exposed to the COVID-19 crisis. We verify that trends in outcomes prior to the FPUC do not correlate with future increases in benefits, which supports our identification assumption. First, we find that a $10 \%$ increase in unemployment benefits caused a 3.6\% decline in applications, but did not decrease vacancy creation; hence, FPUC increased tightness (vacancies/applications). Second, we document that tightness was unusually depressed during the FPUC period. Altogether, our results imply that the positive effect of FPUC on tightness was welfare improving: FPUC decreased competition among applicants at a time when jobs were unusually scarce. Our results also help explain prior findings that FPUC did not decrease employment.

Ioana Marinescu

University of Pennsylvania

School of Social Policy \& Practice

3701 Locust Walk

Philadelphia PA, 19104-6214

and IZA

and also NBER

ioma@upenn.edu

Daphne Skandalis

University of Copenhagen

dskandalis@gmail.com

Daniel Zhao

Glassdoor, Inc.

100 Shoreline Highway, Suite 100 A

Mills Valley, CA 94941

daniel.zhao@glassdoor.com
\end{abstract}




\section{Introduction}

In March 2020, the coronavirus COVID-19 led to a dramatic surge in business closures and job losses. To address this crisis, the Federal Pandemic Unemployment Compensation (FPUC) was voted on March 27 as part of the CARES Act. FPUC provided unemployed workers with an additional $\$ 600$ a week in unemployment benefits, until the end of July 2020. This represented an unprecedented increase in unemployment insurance generosity: $76 \%$ unemployed workers had a replacement rate above $100 \%$ with FPUC, i.e. collected more in unemployment benefits than in their prior wage (Ganong et al., 2020). Economic theory predicts that more generous benefits decrease job search effort and could decrease vacancy creation (Landais et al., 2018b). Therefore, FPUC might have increased unemployment and dampened economic activity, in particular during the summer of 2020, when many lockdown measures were lifted. Yet, the early evidence suggests that there were at most very limited effects on employment (Bartik et al. (2020); Altonji et al. (2020), Dube (2020)). Why? We show that the FPUC did indeed have a negative effect on search effort. However, we provide two pieces of evidence that can explain why FPUC did not decrease employment. First, FPUC did not decrease vacancy creation - not even during the re-opening phase in June-July 2020. Second, labor market tightness was unusually low during FPUC: since jobs were already receiving an unusually high number of applications, a decrease in applications likely had limited effects on the number of workers hired.

Identifying the effect of FPUC is not straighforward. In principle, one can estimate the effect of FPUC on local labor markets by exploiting the large disparities in the proportional increase in unemployment benefits: for workers who would have been eligible to lower weekly benefits levels before the CARES Act, the additional $\$ 600$ per week represents a larger relative increase. However, the passage of the FPUC coincided with exceptionally large and brutal changes in the labor market: just before the implementation of FPUC, the number of job listings collapsed (Forsythe et al., 2020a), while the number of unemployed workers skyrocketed. What is more, workers in low-paying jobs were most likely to lose their jobs, and these workers are precisely the ones who experienced the largest increase in benefits with the FPUC. These shocks are potential confounding factors for the identification of the effect of the FPUC on the labor market. To credibly neutralize them in our empirical analysis, we track labor market outcomes at a very granular level.

We collect detailed data on job applications and job postings from Glassdoor.com, for January 2018 to July 2020. We measure search effort and vacancy creation by counting the number of applications and new job vacancy postings each week, in each local labor market - defined as the interaction of state, occupations and industries and wage deciles. We compute potential replacement rates using the calculator in Ganong et al. (2020). To strengthen the external validity of our analysis, we re-weigh observations such that each State $\times$ industry $\times$ occupation reflects the proportion of the US labor force in that labor 
market in the Current Population Survey (CPS) for 2018-2020.

In the first part of the paper, we estimate the impact of FPUC on search effort, job vacancies and labor market tightness in March-July 2020. We exploit differences in proportional increases in benefits across local labor markets. We include several control variables to flexibly account for changes in the local labor market that were unrelated to the FPUC. We allow for market-specific seasonal variation, using week-of-year by local labor market fixed effects. We include state by week fixed effects to control for differential COVID-19 related policies across states, and other factors that change at the state level. We control for industry by week fixed effects, which accounts for the differential impact of the crisis by industry. Additionally, we allow for different trends in local labor markets that were differentially exposed to unemployment during the COVID-19 crisis prior to the CARES Act. Our identifying assumption is that, in the absence of the policy change, the outcome variables would have evolved similarly in local labor markets with different increases in UI, conditional on controls. We show that future increases in FPUC do not correlate with trends in job applications, job vacancies or labor market tightness in the weeks prior to the enactment of the FPUC. This supports the validity of our identification strategy. We also confirm in robustness checks that our main results hold in the construction sector, where job loss before FPUC was not systematically correlated with earnings (and thus the increase in the replacement rate), and hence identification is less challenging.

We find that a $10 \%$ increase in the benefit replacement rate due to the FPUC leads to a $3.6 \%$ decline in job applications. At the same time, FPUC had no effect on job vacancies. The absence of an effect on vacancy creation indicates that employers' recruiting was not limited by workers' lower search effort or potentially higher wage demands, but rather by other factors, consistent with job rationing models (Michaillat, 2012). Taking the effect on applications and vacancies together, a $10 \%$ in the benefit replacement rate increased labor market tightness by $3.3 \%$. We then analyze the timing of the effect. One could have expected to see a larger impact of FPUC during the reopening phase when most lockdowns were lifted (June-July 2020), since economic activity was picking up. However, FPUC still had no effect on vacancy creation. Further, the effect of FPUC on job applications decreased from May until the end of FPUC in July 2020, suggesting that job seekers might have increased their search effort in anticipation of FPUC expiration.

Our results are similar when we exclude periods of lockdown, or when we focus on teleworkable occupations, which are less affected by social distancing measures. In markets where workers are more likely to be on temporary layoffs, the effects of FPUC on search effort are significantly smaller. This is consistent with the idea that workers are less likely to search when they expect to be recalled, and suggests that the prevalence of temporary layoffs during the COVID-19 crisis might have contributed to attenuating the effect of unemployment insurance on job search.

In the second part of the paper, we describe the context in which FPUC was imple- 
mented, as it is crucial to assess the impact of FPUC on unemployment and welfare. We document the evolution of applications, vacancies, and labor market tightness. During FPUC, seasonally adjusted aggregate applications slightly increased by $4.4 \%$ relative to January-February 2020, despite the negative effect of FPUC on search effort. This probably reflects in part the drastic increase in the number of unemployed workers. At the same time, job vacancies declined by $26 \%$. As a result, labor market tightness decreased by $31 \%$. This implies that on average employers got more applicants for their vacancies, and recruiting was easier. Even in the markets most affected by FPUC (4th quarter of the increase in replacement rate due to FPUC), tightness during the FPUC was $19 \%$ lower than in January-February 2020. During the re-opening period, tightness was only back to its pre-pandemic level, even though many unemployed workers were receiving FPUC as new job openings picked up.

We finally discuss how our results contribute to understanding the welfare impact of the FPUC during the COVID-19 crisis. Landais et al. (2018b) formalize that increases in unemployment insurance improve welfare when unemployment insurance increases tightness note that the effect on tightness depends on the effect on vacancy creation, and is a priori ambiguous - and tightness is inefficiently low. We demonstrate that this is the case for FPUC. First, we show that FPUC did not affect vacancy creation and hence increased tightness. Second, we document that labor market tightness was particularly low during FPUC, suggesting that tightness in the absence of FPUC would have been inefficiently low. Importantly, these results hold for the reopening phase (June-July 2020). Taken together, our results hence indicate that the effect of FPUC on labor market tightness was welfare improving, during the whole period of FPUC. Our paper focuses on welfare considerations that are related to labor market tightness. For a comprehensive welfare analysis of FPUC, one should also take into account the welfare gains associated with limiting the transmission of the virus by avoiding work (Fang et al., 2020), and welfare gains associated with consumption smoothing for UI recipients and the stimulus effect on the economy Ganong et al., 2021). These additional welfare considerations would likely reinforce our conclusion regarding the desirability of high unemployment insurance in the context of FPUC.

Our paper contributes to the body of work analyzing the effects the CARES Act on employment. Several studies show no association between FPUC and employment, either using the Homebase dataset of hourly employees in small businesses (Bartik et al., 2020, Altonji et al., 2020; Finamor and Scott, 2021) or the Census Household Pulse Survey (Dube, 2020). Relative to this literature, we provide two major contributions. First, our data allow us to improve the identification strategy: measuring search effort and vacancy creation instead of employment, and at a very granular level helps us control for changes that are due to the COVID-19 crisis rather than FPUC. Second, we provide a potential explanation for the limited effect of FPUC on employment: FPUC did not affect vacancy creation, and its large negative effect on search effort happened at a time when returns to search 
were particularly low. This complements other explanations for the limited employment effect in the literature. In their models, Boar and Mongey (2020); Petrosky-Nadeau (2020); Mitman and Rabinovich (2021) emphasize that the effect of FPUC on search behavior should be attenuated because unemployed workers anticipated its expiration. Although we find a substantial effect of FPUC on search effort, our finding that it decreased between May and July is consistent with the idea that workers reacted less when they anticipated the expiration. Ganong et al. (2021) show that through a stimulus effect on consumption, FPUC also had a positive effect on employment, which could offset the potential negative effect mediated through the labor market.

Second, this article contributes to the literature on the impact of unemployment benefit levels on job search, and vacancy creation. The increase in the level of benefits with FPUC was exceptionally large (Schmieder and von Wachter, 2016). Yet, our findings are consistent with the estimated effect of unemployment insurance on search effort in prior literature (Krueger and Mueller, 2010; Fradkin and Baker, 2017; Lichter and Schiprowski, 2020). They also confirm the findings of dynamic effects in Marinescu and Skandalis (2021) and DellaVigna et al. (2020). Moreover, our results add to the limited direct evidence on the impact of unemployment benefits on vacancy creation: we find that the number of vacancies was unaffected by the increase in unemployment insurance generosity, similar to what happened during the Great Recession (Marinescu, 2017). This is consistent with the evidence of spillover effects of unemployment benefits extensions (Lalive et al., 2015).

Last, our analysis contributes more generally to the study of the labor market during COVID-19 (Bartik et al., 2020; Gupta et al., 2020; Cheng et al., 2020; Fairlie et al., 2020; Montenovo et al., 2020). We add to work investigating trends in the applications and job postings during COVID in Sweden (Hensvik et al., 2020), and job postings in the US (Forsythe et al., 2020a; Campello et al., 2020; Forsythe et al., 2020b. c).

\section{Data}

We combine several datasets from Glassdoor, one of the world's largest jobs and career sites. We use job vacancy listings and job applications from Glassdoor's online jobs platform in April 2018 to July 2020 for the U.S. We also exploit information on self-reported users' salaries to measure replacement rates.

\subsection{Data on job listings and job applications}

Glassdoor contains job openings that companies post directly to the site, or that are collected on company career sites or third-party job boards. Glassdoor then ties job listings data to specific industries and canonical occupations that can be mapped into O*NETSOC codes. We focus on new job listings posted each week rather than the total stock of 
active job listings. The flow is more responsive to sharp changes in policy and labor market conditions, and captures a disproportionate share of application activity. To measure search effort, we take the count of applications, defined as a user starting an application by clicking on the "Apply Now" button! Applications provide a proxy of search effort, under the assumption that the probability of applying on Glassdoor's website rather than using other search channels is relatively stable over time. We allocate applications into an industry and occupation category based on jobs characteristics, and into a state based on applicants' address. Applications on Glassdoor don't come exclusively from unemployment benefits recipients, therefore our estimates at the local labor market level also capture the search effort of job seekers who do not receive UI. This is the right measure for the purpose of investigating overall labor market tightness. As job seekers who do not receive UI should react less to changes in the generosity unemployment insurance, these market level estimates could be smaller than estimates of the microeconomic impact on the search of UI recipients.

Glassdoor's job listings capture a large portion of online U.S. job listings, which themselves comprise a substantial percentage of all job openings $2^{2}$ Job listings at very small businesses or managed by unions may be underrepresented (Chamberlain and Zhao, 2019). As a result, compared to the Current Population Survey (CPS) labor force by industry in 2018-2020, some sectors like Construction are underrepresented, while other sectors like Information Technology are overrepresented (Table A.1). We hence use weights in all our analysis, based on the average number workers in the labor force in the industry, occupation and state from the CPS for January 2018- July 2020. We confirm that weighted job listings evolve very similarly - the correlation is 0.6 for 2019-2020 - to vacancies in the representative Job Openings and Labor Turnover Survey (JOLTS) (Figure A.2). In particular, the magnitude of the decrease in job listings in April and May 2020 is the same in the two data sources.

\subsection{Data on earnings and unemployment benefits}

To study the role of UI generosity, we need to determine the "potential replacement rates" for job seekers in our sample, i.e. the replacement rates that those eligible for unemployment insurance would receive at each point in time. The replacement rate level in normal times depends on rules specific to each state. We use the benefits calculator created by Ganong et al. (2020), which computes unemployment benefits based on individuals' state of residence and pre-displacement quarterly earnings based on UI guidance provided by

\footnotetext{
${ }^{1}$ The data is a subset of total applications on Glassdoor. To enhance data quality, Glassdoor's data processing retains likely people (not bots) who apply after organically searching for jobs on Glassdoor (rather than being redirected to the job posting from elsewhere, e.g. from Glassdoor emails or from paid advertisements on other sites).

${ }^{2}$ The count of job openings reported in Glassdoor's Job Market Report represents $81 \%$ of the count job openings reported in the Job Openings and Labor Turnover Survey.
} 
the Department of Labor. We add $\$ 600$ to standard weekly benefits levels to compute the replacement rate with the FPUC.

We need two key pieces of information to compute the standard weekly benefits level: the average weekly earnings before unemployment and the number of days worked for each quarter in the year before unemployment. For wages, we use earnings self-reported by Glassdoor users. Although it is not required to search for jobs on the platform, some Glassdoor users report information on their wage, including base salary and additional compensation like tips and cash bonuses? We take the average prior earnings for each state-occupation, using a very disaggregated occupation definition ( $\mathrm{O}^{*}$ Net 6 -digit codes, 416 categories) 4 The second piece of information we need to infer workers' potential replacement rate is the number of days worked in each quarter of the year before unemployment. We assume that individuals worked continuously during the four quarters preceding unemployment.5

\subsection{Panel at the week and local labor market level}

We arrange our data as a panel, at the calendar week and local labor market level. To be able to add granular fixed effects to our regressions, we define a local labor market as the interaction of state, 2-digit occupations (76 categories in our sample), 2-digit industries (12 categories in our sample) and wage deciles. We keep local labor markets with at least 1000 applications in 2018-2020, such that we can detect variation in weekly applications count (our results are robust to using alternative thresholds). We present descriptive statistics for the main variables in Table A.2.

\section{Institutional background and empirical strategy}

\subsection{Institutional background}

The CARES Act was signed into law on March 27 2020. As part of the CARES Act, the Federal Pandemic Unemployment Compensation (FPUC) was an additional $\$ 600$ a week of unemployment benefits for all workers eligible to unemployment insurance. The FPUC was also available to workers who are not normally eligible for benefits, but were eligible for Pandemic Emergency Unemployment Compensation (PEUC) benefits or Pandemic Unemployment Assistance (PUA) benefits. PEUC provided an additional 13 weeks of benefits for those whose regular unemployment benefits have been exhausted. PUA provided

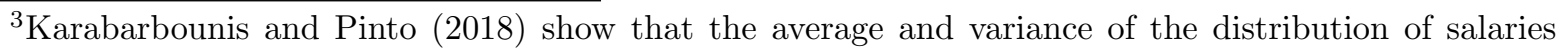
within geographical region and within industry are fairly representative when compared against the Quarterly Census of Employment and Wages and Panel Study of Income Dynamics.

${ }^{4}$ We do not use industry for prior earnings because the cells become very small and most of the variation in wages is explained by our narrow occupation categories in our data.

${ }^{5}$ This is the case for most individuals eligible for unemployment insurance, given the average number of days worked reported in the 2019 Annual Social and Economic Supplement (ASEC) of the CPS.
} 
payment to workers not traditionally eligible for unemployment benefits (self-employed, independent contractors, workers with limited work history, and others) who were unable to work as a direct result of the coronavirus public health emergency. The $\$ 600$ FPUC amount was chosen to raise the UI replacement rate to $100 \%$ for the average U.S. worker. Because of technical issues in state unemployment insurance systems, it was not possible to tailor FPUC to each worker's prior earnings. Once the CARES Act was voted, on March 27, unemployed workers could anticipate their upcoming replacement rate, and potentially adjust their behavior accordingly. But it took a few weeks, until the end of April, for all states to start paying out benefits (Bartik et al., 2020). The last FPUC payment was the week of July 20, 2020.

\subsection{Empirical strategy}

Variation in the increase in replacement rate For identification, we exploit the large disparities in the magnitude of the increase in replacement rate. They mostly come differences in pre-displacement earnings: with a fixed $\$ 600$ increase in benefits, unemployed workers with low prior wages experienced a larger increase in replacement rate 6 We focus on the estimation of impact of the relative increase in replacement rate, in order to calculate elasticities. We leverage differences in the relative increase in replacement rate across local labor markets. Because our local labor markets are relatively narrow, they capture a lot of the variation in pre-displacement earnings. In particular, we capture the variation in earnings across occupations, and even within occupation due to seniority and specialization (Marinescu and Wolthoff, 2019).

Identification strategy We can identify the effect of the increase in replacement rate under the assumption that, in the absence of a change in unemployment insurance, the outcome variable would have evolved similarly in local labor markets with different increases in UI (conditional on controls). The identification of the effect of FPUC on the outcome variables is threatened by any factor that affects the outcomes around the date of the CARES Act and correlates with the increase in UI generosity. The enactment of FPUC coincided with an exceptionally large and abrupt negative labor market shock due to COVID-19. In March, employment decreased precipitously and unemployment skyrocketed (appendix Figure A.1). This shock disproportionately hit low-paying jobs, and hence workers who experienced the largest increase in their potential replacement rate due to FPUC. Therefore, failing to account for this shock would likely bias estimates of the causal effect of FPUC on aggregate labor market outcomes. We address this identification challenge in several ways.

First, we control for various observable variables to absorb the effect of the COVID-19 crisis, or other potential confounders. We include week-of-year $\times$ local labor market fixed

\footnotetext{
${ }^{6}$ This is true both in absolute terms (i.e. the additional benefit over their prior wage is larger) and in relative terms (i.e. the additional benefit over their unemployment benefit without FPUC is larger).
} 
effects, to flexibly allow for seasonal variation in each local labor market. As the COVID-19 crisis hit different states and industries in different ways, we include time $\times$ state fixed effects, and time $\times$ industry fixed effects. We also take a different approach, and try to directly quantify the exposure to the COVID-19 crisis in each local labor market. We estimate the risk of unemployment immediately prior to the CARES Act. Using the monthly CPS for January to March 2020 matched with the Outgoing Rotation Group 2019 (ORG) (Flood et al. 2020), we predict the probability of being unemployed for individuals in the labor force, in a logit model including industry, occupation, wage decile and state fixed effects. We use the estimated coefficients to predict the risk of unemployment in our sample. We allow for different trends in markets differentially exposed to the COVID-19 crisis in our estimation model, by including exposure decilexindustry fixed effects.7. Figure A.3 shows that substantial variation in the increase in replacement rate remains even once we take out the portion explained by state, industry, and by exposure decile.

Second, we test the plausibility of our identifying assumption by analyzing the correlation between the evolution of outcomes before the CARES Act, and the magnitude of the benefits increase induced by FPUC. If our identification strategy is valid, our pre-CARES Act estimates should not be significant. This is equivalent to the test of the parallel trend assumption in a differences-in-differences setup.

Third, we conduct a robustness check where we focus on a segment of the economy where identification problems appear less severe. Specifically, we analyze the correlation or prior earnings with the probability of becoming unemployed at the onset of the COVID-19 crisis, by sector, using the CPS for January-March 2020, matched with ORG 2019. Consistent with descriptive statistics presented in Figure A.1, there is a strong negative relationship between prior earnings and the risk of unemployment (Table A.3), but this correlation is small and insignificant in the Construction sector (in the Mining sector as well, but there is virtually no applications for this sector on Glassdoor). We hence re-estimate the effect of FPUC for Construction, using the same empirical model without including week by state, week by industry and week by exposure fixed effects 8 The estimates give the causal effect of FPUC, without imposing any functional form to the confounding effect of the COVID-19 crisis on outcomes, under the alternative identifying assumption that there is no substantial confounding factor in this sector.

Estimation models We estimate the following model:

\footnotetext{
${ }^{7}$ We use exposure deciles for more flexibility, but our results are completely similar if we instead control linearly for exposure $\times$ week.

${ }^{8}$ There is substantial variation in earnings across frequent occupations in the construction sector in CPSORG: for instance, they range around $\$ 1410$ for community association managers ; $\$ 1020$ for electricians ; $\$ 960$ for construction laborers.
} 


$$
\begin{array}{r}
\ln \left(Y_{t, s, o, i, w}\right)=\sum_{\tau \neq-1} \beta_{\tau} \cdot \mathbb{1}[t=F P U C+\tau] \cdot \ln \left(\frac{\operatorname{Rep} F P U C}{\operatorname{Rep}}\right)_{s, o, i, w}+ \\
\lambda_{\text {week }(t), s, o, i, w}+\rho_{s, t}+\phi_{i, t}+\psi_{t, \operatorname{Exposure}(s, o, i, w)}+\varepsilon_{t, s, o, i, w}
\end{array}
$$

$\ln \left(\frac{\operatorname{Re} p_{F P U C}}{\operatorname{Rep}}\right)_{s, o, i, w}$ gives the relative increase in the replacement rate associated with FPUC in each local labor market, defined as the intersection of a state $s$, an occupation $o$, an industry $i$ and a wage decile $w \cdot \ln \left(Y_{t, s, o, i, w}\right)$ denotes the logged outcome variable in calendar week $t$ (to avoid missing values, we add 1 to each outcome before taking the log). $\mathbb{1}[t=F P U C+\tau]$ indicates that the calendar week $t$ is $\tau$ weeks before the start of FPUC (for $\tau<0$ ), or after (for $\tau \geq 0$ ). We take as reference period $\tau=-1$, i.e. the week before the start of FPUC (we consider that FPUC starts with the CARES Act, the week of March 23, 2020). The $\beta_{\tau}$ are the coefficients of interest. We include week-of-year $\times$ local labor market fixed effect, $\lambda_{\text {week }(t), s, o, i, w}$; we let time $t$ fixed effects vary by state $\left(\rho_{s, t}\right)$, industry $\left(\phi_{i, t}\right)$ and Exposure decile $\left(\psi_{t, \text { Exposure }(s, o, i, w)}\right) \cdot \varepsilon_{t, s, o, i, w}$ is the error term. We cluster standard errors at the state level, and observations are weighted by the average number workers in the labor force in the industry, occupation and state from the CPS for January 2018- July 2020.

\section{The impact of FPUC on the labor market}

\subsection{Main results}

Pre-FPUC trends Figure 1 presents the correlation between labor market outcomes and the increase in UI generosity induced by FPUC, week by week. We present our preferred specification, including the full set of controls: time $\times$ state fixed effects, time $\times$ industry fixed effects and time $\times$ Exposure decile fixed effects. There is no significant correlation between applications and future benefits increases in weeks prior to the adoption of FPUC. This supports the credibility of our identifying assumption that, in the absence of FPUC, the evolution of outcomes would be similar in markets that experienced different benefits increases, conditional on the control variables included. Under this assumption, the coefficients for the period after the adoption of FPUC can be interpreted as the causal effect of FPUC. 
Figure 1: The impact of FPUC on applications, vacancies and tightness, week by week

(1) Applications

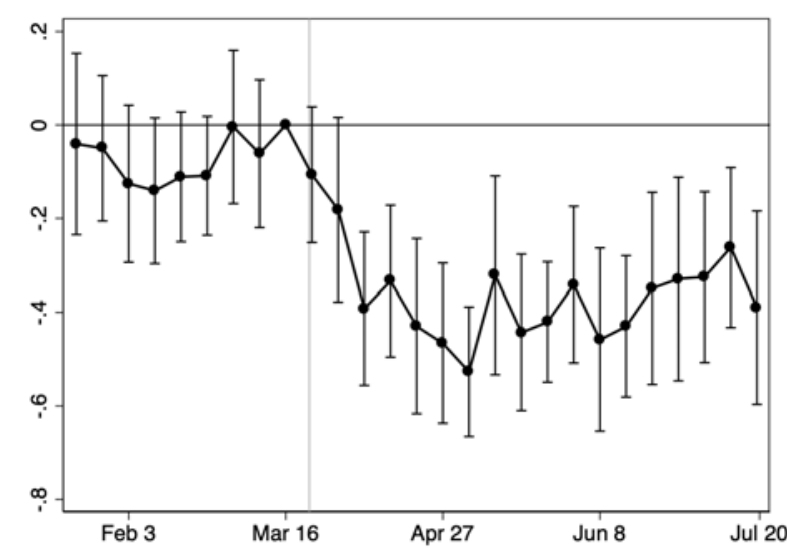

(2) Vacancies

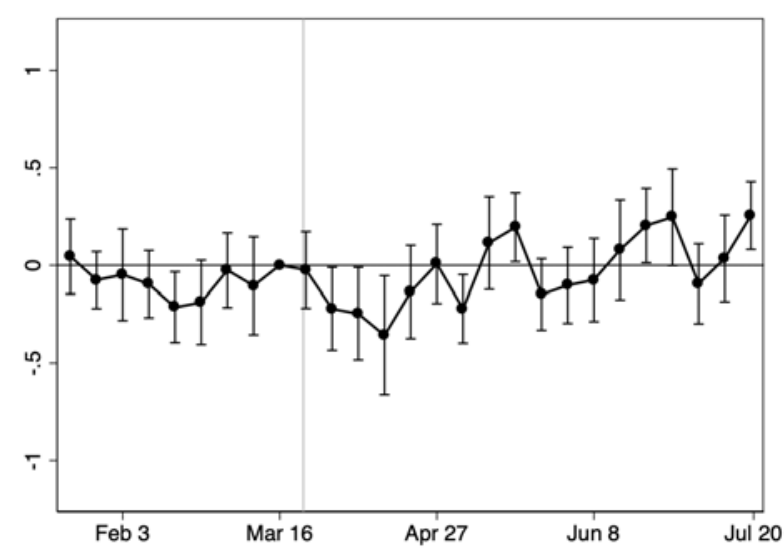

(3) Labor market tightness

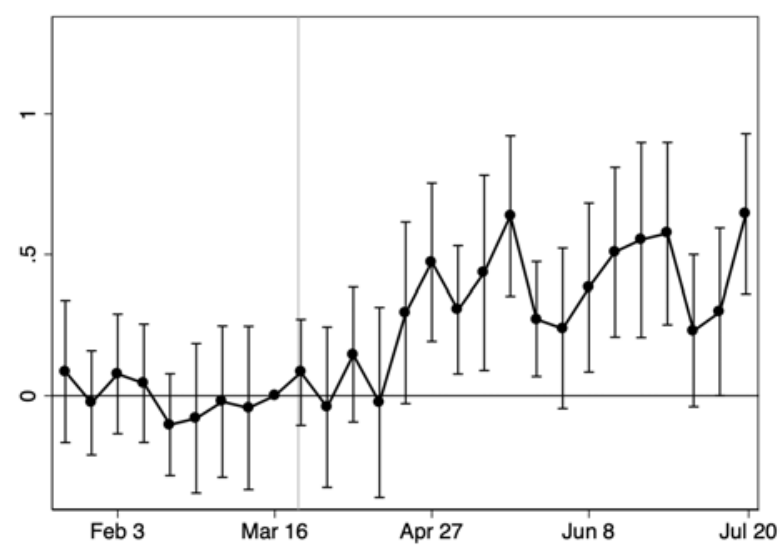

Notes: This Figure reports the estimates from regressions of the logged count of applications, the logged count of vacancies, and the logged labor market tightness (i.e. ratio of vacancies over applications) on the interaction of each week around the enactment of the FPUC and the potential increase in UI generosity $\ln \left(\frac{\operatorname{Re} p_{F P U C}}{R e p}\right)$. The coefficients before the enactment of the FPUC help test our identification assumption. The coefficients after represent the elasticity of the outcome with respect to benefits levels. We use a panel at the calendar week and local labor market level - where local labor markets are defined as as the interaction of state, 2-digit occupations and 2-digit industries and wage deciles. We include calendar week and local labor market fixed effects. We control for seasonality using week-of-year $\times$ local labor market fixed effects. This Figure presents our preferred specification, with the full set of controls for potential confounders: time $\times$ state fixed effects, time $\times$ industry fixed effects and time $\times$ Exposure deciles fixed effects. We use weights to reflect the proportion of the labor force in each Statexindustry $\times$ occupation in the CPS. Thin lines denote $95 \%$ confidence intervals, based on robust SE clustered at the state level. 
The effect of FPUC The increase in unemployment insurance generosity leads to a decrease in applications immediately after the CARES Act, which remains visible until FPUC expires (Figure 1, (1)). Quantitatively, Table 1 shows that the corresponding elasticity of applications with respect to the benefit replacement rate is -0.36 , (col. (1)): a $10 \%$ increase in the replacement rate leads to a $3.6 \%$ decline in job applications, consistent with the theoretical prediction that a higher benefit replacement rate decreases search effort. In contrast, FPUC had no clear effect on job vacancies (Figure 1 (2)). While there is a decrease in the number of vacancies immediately after FPUC was voted and until mid-April, it is only transitory and imprecisely estimated. Since FPUC decreased applications and had no effect on vacancies, it increased labor market tightness (Figure 1, (3)). Consistently, we see in column (2) of Table 1 that the elasticity of vacancies with respect to the replacement rate is close to zero and statistically insignificant. Column (3) shows that the elasticity of tightness (vacancies/applications) is therefore close to the opposite of the elasticity of applications: a $10 \%$ increase in the benefit replacement rate leads to a $3.34 \%$ increase in labor market tightness.

Table 1: Elasticity of search with respect to benefits levels

\begin{tabular}{|c|c|c|c|}
\hline & $\begin{array}{c}\text { Applications } \\
(\ln )\end{array}$ & $\begin{array}{c}\text { Vacancies } \\
(\ln )\end{array}$ & $\begin{array}{c}\text { Tightness } \\
(\ln )\end{array}$ \\
\hline & $(1)$ & $(2)$ & $(3)$ \\
\hline $\ln \left(\frac{\operatorname{Rep}_{F P U C}}{\operatorname{Rep}}\right) \times \mathrm{FPUC}$ period & $\begin{array}{c}-0.361^{* * *} \\
(0.071)\end{array}$ & $\begin{array}{l}-0.027 \\
(0.069)\end{array}$ & $\begin{array}{c}0.334^{* * *} \\
(0.106)\end{array}$ \\
\hline Exposure decile $\times$ Time FE & $\checkmark$ & $\checkmark$ & $\checkmark$ \\
\hline Industry $\times$ Time FE & $\checkmark$ & $\checkmark$ & $\checkmark$ \\
\hline State $\times$ Time FE & $\checkmark$ & $\checkmark$ & $\checkmark$ \\
\hline Labor market $\times$ Week of year FE & $\checkmark$ & $\checkmark$ & $\checkmark$ \\
\hline No. of Obs & $1,523,252$ & $1,523,252$ & $1,523,252$ \\
\hline
\end{tabular}

Notes: This Table reports the estimated elasticity of job applications, vacancy creation and labor market tightness (vacancies/applications) with respect to unemployment benefits levels. The estimates are obtained from the regression of logged labor market outcomes on the logged increase in benefits interacted with a dummy for the period between the vote of FPUC and its expiration, in a panel at the calendar week and local labor market level-where local labor markets are defined as as the interaction of state, 2-digit occupations and 2-digit industries and wage deciles. We use weights to reflect the proportion of the labor force in each State $\times$ industry $\times$ occupation in the CPS. Robust standard errors clustered at the state level are in parenthesis ${ }^{*} \mathrm{p}<0.10$, $^{* *}$ $\left.\mathrm{p}<0.05,{ }^{* * *} \mathrm{p}<0.010\right)$.

\subsection{Additional results}

We first analyze the timing of the effect of FPUC on search effort. In Figure 1 (panel (1)), we see that the negative effect on search strongly increased in the first 3 weeks, possibly due to delays in initial benefit receipt. The effect then remained roughly constant until June, 
Table 2: Additional results on the impact of FPUC on applications

\begin{tabular}{|c|c|c|c|c|}
\hline & \multicolumn{4}{|c|}{ Applications $(\ln )$} \\
\hline & $(1)$ & $(2)$ & $(3)$ & $(4)$ \\
\hline $\ln \left(\frac{\operatorname{Re} p_{F P U C}}{R e p}\right) \times$ FPUC period, March & $\begin{array}{c}-0.144^{*} \\
(0.079)\end{array}$ & & & \\
\hline $\ln \left(\frac{\operatorname{Re} p_{F P U C}}{\operatorname{Rep}}\right) \times \mathrm{FPUC}$ period, April & $\begin{array}{c}-0.385^{* * *} \\
(0.075)\end{array}$ & & & \\
\hline $\ln \left(\frac{\operatorname{Re} p_{F P U C}}{R e p}\right) \times$ FPUC period, May & $\begin{array}{c}-0.436^{* * *} \\
(0.065)\end{array}$ & & & \\
\hline $\ln \left(\frac{\operatorname{Re} p_{F P U C}}{R e p}\right) \times$ FPUC period, June & $\begin{array}{c}-0.395^{* * *} \\
(0.080)\end{array}$ & & & \\
\hline $\ln \left(\frac{\operatorname{Re} p_{F P U C}}{R e p}\right) \times$ FPUC period, July & $\begin{array}{c}-0.326^{* * *} \\
(0.085)\end{array}$ & & & \\
\hline $\ln \left(\frac{\operatorname{Re} p_{F P U C}}{\operatorname{Rep}}\right) \times$ FPUC period $\times$ Lockdown & & $\begin{array}{c}-0.356^{* * *} \\
(0.070)\end{array}$ & & \\
\hline $\ln \left(\frac{\operatorname{Rep}_{F P U C}}{\operatorname{Rep}}\right) \times$ FPUC period $\times$ Open & & $\begin{array}{c}-0.368^{* * *} \\
(0.075)\end{array}$ & & \\
\hline $\ln \left(\frac{\operatorname{Re} p_{F P U C}}{R e p}\right) \times$ FPUC period, Telework & & & $\begin{array}{c}-0.382^{* * *} \\
(0.100)\end{array}$ & \\
\hline $\ln \left(\frac{\operatorname{Rep}_{F P U C}}{\operatorname{Rep}}\right) \times \mathrm{FPUC}$ period, Not telework & & & $\begin{array}{c}-0.311^{* * *} \\
(0.086)\end{array}$ & \\
\hline FPUC period $\times$ Telework & & & $\begin{array}{c}0.131 \\
(0.141)\end{array}$ & \\
\hline $\ln \left(\frac{\operatorname{Re} p_{F P U C}}{R e p}\right) \times$ FPUC period, High temp layoff & & & & $\begin{array}{c}-0.173^{* *} \\
(0.080)\end{array}$ \\
\hline $\ln \left(\frac{\operatorname{Re} p_{F P U C}}{R e p}\right) \times$ FPUC period, Low temp layoff & & & & $\begin{array}{r}-0.414^{* * *} \\
(0.075)\end{array}$ \\
\hline FPUC period $\times$ High temp layoff & & & & $\begin{array}{c}-0.361^{* * *} \\
(0.107)\end{array}$ \\
\hline P-Value Test May = July & .013 & & & \\
\hline P-Value Test Lockdown = Open & & .702 & & \\
\hline P-Value Test Telework $=$ Not telework & & & .554 & \\
\hline P-Value Test High temp layoff $=$ Low temp layoff & & & & .009 \\
\hline Exposure decile $\times$ Time FE & $\checkmark$ & $\checkmark$ & $\checkmark$ & $\checkmark$ \\
\hline Industry $\times$ Time FE & $\checkmark$ & $\checkmark$ & $\checkmark$ & $\checkmark$ \\
\hline State $\times$ Time FE & $\checkmark$ & $\checkmark$ & $\checkmark$ & $\checkmark$ \\
\hline Labor market $\times$ Week of year FE & $\checkmark$ & $\checkmark$ & $\checkmark$ & $\checkmark$ \\
\hline No. of Obs & $1,523,252$ & $1,523,252$ & $1,496,988$ & $1,523,252$ \\
\hline
\end{tabular}

Notes: This Table reports the estimates from the regression of logged search effort on various independent variables, in a panel at the calendar week and local labor market level-where local labor markets are defined as as the interaction of state, 2-digit occupations and 2-digit industries and wage deciles. We use weights to reflect the proportion of the labor force in each State $\times$ industry $\times$ occupation in the CPS. Robust standard errors clustered at the state level are in parenthesis $\left(* \mathrm{p}<0.10,{ }^{* *} \mathrm{p}<0.05,{ }^{* * *} \mathrm{p}<0.010\right)$.

and decreased until the end of FPUC. The estimated elasticity is -0.44 in May, at its largest; in July, as the extra benefits are about to expire, the elasticity is significantly smaller (in absolute value) at -0.33 (Table 2, col. 1) $9^{9}$ Our results are consistent with theory predicting

\footnotetext{
${ }^{9}$ We present the estimates from the same specifications for vacancies and tightness in A.4
} 
that job seekers increase their search effort as benefits expiration approaches (Marinescu and Skandalis, 2021), and therefore that increases in unemployment insurance have smaller effects on job search when workers anticipate that they are temporary Boar and Mongey, 2020; Petrosky-Nadeau, 2020; Mitman and Rabinovich, 2021).

Over time, the economic environment also changed with many states adopting lockdown measures in March that were later relaxed. As these measures could hinder economic activity, one could expect the impact of unemployment insurance on the labor market to be attenuated during lockdowns. The elasticity of search with respect to unemployment insurance was slightly smaller when states implemented a lockdown, but the difference is small and insignificant (Table 2 col. (2)). This suggests that the difference in the effect of unemployment insurance on search over time is not explained by lockdown measures, but rather by unemployed workers' anticipation of FPUC expiration. In Appendix A.4 (col. (2)) we also show that if anything, there is more of a negative effect on vacancy creation during lockdowns (although the estimate is insignificant).

One could expect that the reaction of job seekers to the increase in unemployment insurance was smaller than in normal times, because the risk of contamination with COVID-19 imposed constraints on search and on work. Yet, we find little evidence for this: in Table 2 (col. 3), we show that the effect of FPUC on search effort is similar in "teleworkable" and non- "teleworkable" occupations (defined as in Dingel and Neiman (2020)).

The situation of unemployed workers during the COVID-19 crisis was also atypical in that a large fraction of them were on temporary layoff (Birinci et al., 2021). We estimate the chance to be on temporary layoff in the CPS for January to July 2020 conditional on being unemployed, in a logit model with two-digit occupation, two-digit industry, state and wage decile fixed effects. We predict the probability of temporary layoff among unemployed workers in each local labor market based on the estimated coefficients. In Table 2 (col. (4)), we show that the effect of FPUC on search effort is significantly smaller in markets with a high (above median) chance of temporary layoff (elasticity of -0.17) than in the others (elasticity of -0.41). It suggests that the prevalence of temporary layoffs has contributed to attenuating the effect of FPUC on job search, since workers who expect to be recalled are search less irrespective of their unemployment insurance.

\subsection{Robustness checks}

To illustrate the role of the controls we include in our favorite specification, we present estimates when we add them one by one in Figure A.4. Figure A.5 and Figure A.6. All control variables contribute to making the pre-trends disappear, in line with the economic intuitions behind our estimation strategy. For instance, when we only control for seasonality, the coefficients in panel (2) of Figure A.4 exhibit a steep increase in the weeks before the CARES Act, which might reflect the abrupt surge in unemployment among low-wage 
workers. Although the different controls seem to improve our identification of the effect of FPUC, it is reassuring to note that our qualitative conclusions do not crucially depend on one particular specification. The estimates obtained in all the specifications in A.4 are suggestive of a negative effect of FPUC on job search. None of the specifications in Figure A.5 provide any indication of a negative effect on vacancy creation. Finally, all specifications in Figure A.6 are suggestive of a positive effect of FPUC on tightness.

We then analyze more flexibly the relationship between labor market outcomes and the increase in unemployment benefits induced by FPUC in Table A.5. We look separately at the evolution of outcomes in local labor markets at different quartiles of the distribution of relative increase in benefits in columns (1)-(3). As expected, the largest increase in unemployment benefits was associated with the largest decrease in applications. The effect for the third and fourth quartile is essentially the same, suggesting there is no additional decrease in applications for very high increases in the replacement rate. In columns (4)(6) we estimate the effect of the absolute increase in replacement rates. The results are qualitatively similar.

Finally, to confirm our main results, we focus on the construction sector, where job loss before FPUC was not systematically correlated with earnings. While the estimates are naturally less precise than in the full sample, we see similar qualitative patterns: FPUC decreased applications, had no effect on vacancies, and therefore ultimately increased labor market tightness (Figure A.7). These results are reassuring: our key results hold in a segment of the economy where there are no substantial factors confounding the identification of the effect of FPUC.

\section{$5 \quad$ Labor market tightness during the FPUC}

In order to fully understand the impact of FPUC, we now document the labor market situation when it was introduced.

\subsection{The evolution of labor market tightness}

We present the evolution of seasonally adjusted applications, new vacancy postings, and labor market tightness relative to their baseline levels in Jan-Feb 2020 in Figure 2. The number of vacancies strongly declined both before and right after FPUC. In contrast, the number of job applications exhibited limited change. This suggests that the various factors that could influence search in that period (the increase in unemployment, FPUC, the infection risk, uncertainty, etc.) largely compensated each other ${ }^{10}$ Therefore the decline in vacancies entirely drove the evolution of labor market tightness.

\footnotetext{
${ }^{10}$ In the non seasonally adjusted series (Figure A.8 left panel), applications decline a bit after FPUC, but this pattern occurs every year (appendix Figure A.9).
} 
Figure 2: Changes in applications, vacancies, and labor market tightness relative to Jan-Feb 2020 (seasonally adjusted)

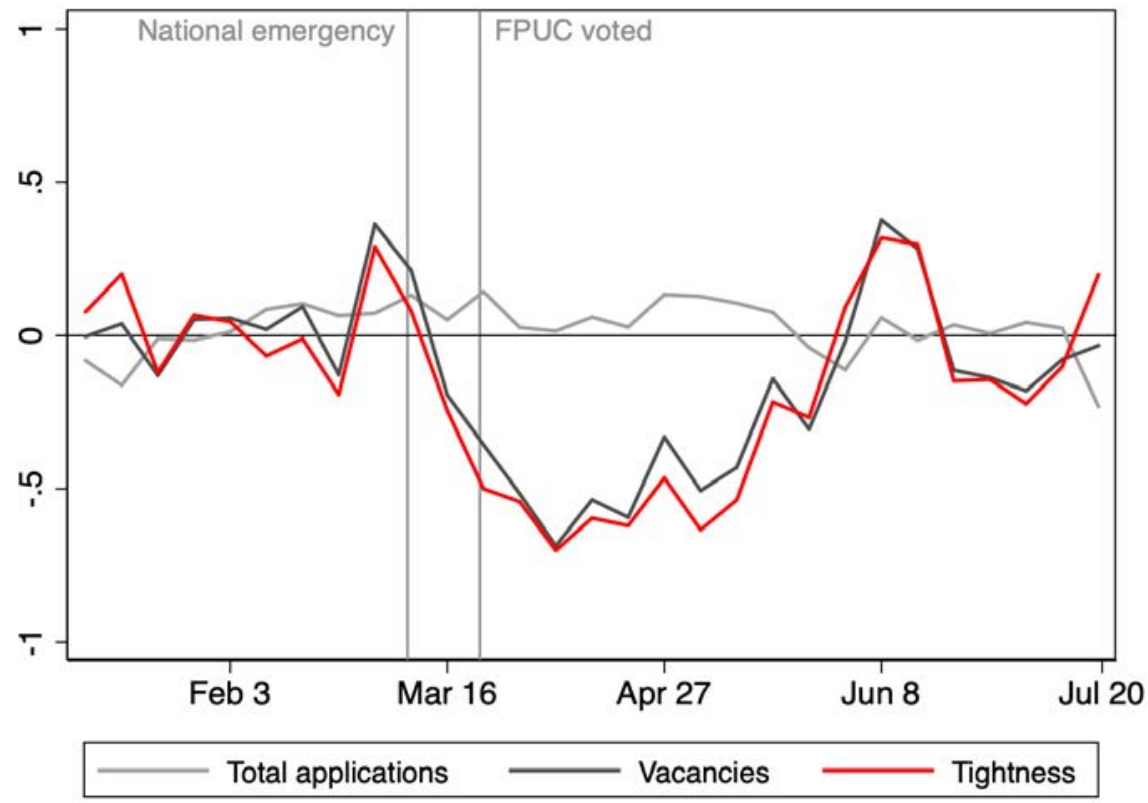

Notes: The Figure presents the seasonally adjusted changes in the total weekly count of applications, the weekly count of new posted vacancies, and labor market tightness (ratio of vacancies over total applications), relative to their baseline levels in Jan-Feb 2020. The Figure is obtained by regressing the logged variables on the calendar week coefficients and week-of-year fixed effects to control for seasonal variation, and then subtracting to each calendar week coefficient the average of estimates for Jan-Feb 2020. We use weights to reflect the proportion of the labor force in each State $\times$ industry $\times$ occupation in the CPS. 
Quantitatively, seasonally adjusted labor market tightness declined by $30.6 \%$ during the FPUC period relative to January-February 2020 (Table 3, col. 3, upper panel), reflecting a labor market more favorable to recruiting firms, despite the large increase in unemployment benefits. During the whole FPUC period, applications slightly increased by $4.4 \%$ (col. 1, upper panel), while vacancies declined by $26.2 \%$ (col. 2). During the reopening phase, in June-July 2020, seasonally adjusted applications, vacancies, and labor market tightness were similar to their level in Jan.-Feb. 2020 (col. 1-3, lower panel). Overall, the evidence is not consistent with significant hiring difficulties during the reopening phase 11

Table 3: Changes in labor market tightness during the period of the FPUC, relative to Jan-Feb 2020

\begin{tabular}{|c|c|c|c|c|c|c|c|}
\hline \multirow{3}{*}{$\begin{array}{l}\text { Sample: } \\
\text { Outcome: }\end{array}$} & \multirow{2}{*}{\multicolumn{3}{|c|}{ All }} & \multicolumn{4}{|c|}{ Potential increase in UI } \\
\hline & & & & \multirow{2}{*}{$\frac{\text { Q1 }}{\text { Tightness }}$} & \multirow{2}{*}{$\frac{\text { Q2 }}{\text { Tightness }}$} & \multirow{2}{*}{$\frac{\text { Q3 }}{\text { Tightness }}$} & \multirow{2}{*}{$\frac{\mathrm{Q} 4}{\text { Tightness }}$} \\
\hline & Applications & Vacancies & Tightness & & & & \\
\hline & $(1)$ & $(2)$ & $(3)$ & $(4)$ & $(5)$ & $(6)$ & $(7)$ \\
\hline FPUC period & $\begin{array}{c}0.044^{* *} \\
(0.018)\end{array}$ & $\begin{array}{c}-0.262^{* * *} \\
(0.022)\end{array}$ & $\begin{array}{c}-0.306^{* * *} \\
(0.021)\end{array}$ & $\begin{array}{c}-0.413^{* * *} \\
(0.023)\end{array}$ & $\begin{array}{c}-0.334^{* * *} \\
(0.024)\end{array}$ & $\begin{array}{c}-0.287^{* * *} \\
(0.046)\end{array}$ & $\begin{array}{c}-0.190^{* * * *} \\
(0.032)\end{array}$ \\
\hline Week of year FE & $\checkmark$ & $\checkmark$ & $\checkmark$ & $\checkmark$ & $\checkmark$ & $\checkmark$ & $\checkmark$ \\
\hline No. of Obs & $1,540,598$ & $1,540,598$ & $1,540,598$ & 613,586 & 412,050 & 297,346 & 217,616 \\
\hline FPUC, Mar-May & $\begin{array}{c}0.076^{* * *} \\
(0.021)\end{array}$ & $\begin{array}{c}-0.448^{* * *} \\
(0.023)\end{array}$ & $\begin{array}{c}-0.524^{* * *} \\
(0.021)\end{array}$ & $\begin{array}{c}-0.547^{* * *} \\
(0.023)\end{array}$ & $\begin{array}{c}-0.558^{* * *} \\
(0.021)\end{array}$ & $\begin{array}{c}-0.547^{* * *} \\
(0.048)\end{array}$ & $\begin{array}{c}-0.444^{* * *} \\
(0.035)\end{array}$ \\
\hline FPUC, Jun-Jul & $\begin{array}{c}0.004 \\
(0.019)\end{array}$ & $\begin{array}{l}-0.030 \\
(0.022)\end{array}$ & $\begin{array}{l}-0.034 \\
(0.025)\end{array}$ & $\begin{array}{c}-0.246^{* * *} \\
(0.028)\end{array}$ & $\begin{array}{l}-0.055 \\
(0.040)\end{array}$ & $\begin{array}{c}0.039 \\
(0.054)\end{array}$ & $\begin{array}{c}0.126^{* * *} \\
(0.037)\end{array}$ \\
\hline Week of year FE & $\checkmark$ & $\checkmark$ & $\checkmark$ & $\checkmark$ & $\checkmark$ & $\checkmark$ & $\checkmark$ \\
\hline No. of Obs & $1,540,598$ & $1,540,598$ & $1,540,598$ & 613,586 & 412,050 & 297,346 & 217,616 \\
\hline
\end{tabular}

Notes: This Table reports changes in the count of job applications, the count of new posted vacancies, and labor market tightness during the period of the FPUC, relative to their baseline levels in Jan-Feb 2020. In the upper panel, we present estimates for the total period of FPUC, while we divide the FPUC period in two sub-periods in the lower panel. The estimates are obtained by regressing each logged outcome on dummy variables for the FPUC period and for all calendar weeks outside of the baseline period of January-February 2020, in a panel at the calendar week and local labor market level. We include week-of-year fixed effects to control for seasonal variation. The estimates are obtained in the full sample in col. (1)-(3), and separately for local labor markets in each quartile of the distribution of potential UI increase in col. (4)-(7). We use weights to reflect the proportion of the labor force in each Statexindustry $\times$ occupation in the CPS. Robust standard errors clustered at the state level are in parenthesis ${ }^{*} \mathrm{p}<0.10,{ }^{* *}$ $\left.\mathrm{p}<0.05,{ }^{* * *} \mathrm{p}<0.010\right)$.

\footnotetext{
${ }^{11}$ In JOLTS, the hiring rate was above its pre-COVID levels in June-July 2020, in line with our findings.
} 


\section{$5.2 \quad$ Heterogeneity}

One could be concerned that recruitment difficulties increased in the local labor markets most affected by FPUC. We present the evolution of tightness by quartile of the increase in replacement rate due to FPUC, in columns 4-7 of Table 3 and graphically in Figure A.10. We show that even in the markets most affected by FPUC, seasonally adjusted tightness was 19\% lower during FPUC than at baseline (Table 3, col. 7). During the re-opening phase, tightness for the fourth quartile was slightly higher $(12.6 \%)$ than at baseline. For the three lower quartiles (col. 4-6), tightness during reopening remained below or at baseline. Finally, Figure A.11 and Figure A.12 show that the evolution of applications, vacancies and labor market tightness are qualitatively similar across sectors. The magnitudes of the fluctuations differ by sector in expected ways: for example, during the lockdown, vacancies in sectors that were directly affected like leisure \& hospitality and transport \& logistics understandably decreased more than in other sectors. In leisure \& hospitality, applications also declined during the FPUC period, suggesting that workers might have decreased their search due to infection risk. In construction, which we analyzed above, the evolution of tightness is similar to that in other sectors.

\section{Discussion}

\subsection{Model of the labor market}

We discuss how our results help understand the functioning of the labor market during the start of the COVID-19 crisis. Although most models predict that more generous unemployment insurance should decrease search, one important question in general equilibrium models is to which extent unemployment benefits affect vacancy creation, and hence labor market tightness (Landais et al., 2018b). In standard models, higher unemployment benefits diminish job search and exert upward pressure on wages by raising the outside option of unemployed workers, thereby discouraging vacancy creation (Pissarides, 2000). In "job rationing" models, vacancy creation primarily depends on the marginal product of labor, and is hence unaffected by unemployment insurance (Michaillat, 2012). Our finding that FPUC did not affect vacancy creation is consistent with job rationing. What is the economic intuition? In the context of the COVID-19 crisis, the marginal product of a worker might have been pushed down by social distancing measures. Other factors less specific to the COVID-19 crisis might have also contributed to the job rationing, since we detect no effect on vacancy creation even after lockdown measures were lifted, and even for teleworkable occupations. Evidence of job rationing were also found in other recessions (Lalive et al., 2015, Marinescu, 2017; Landais et al., 2018a).

In job rationing models, unemployment insurance has more limited effects on employment (Landais et al., 2018b): because UI increases labor market tightness, it decreases 
the competition among job seekers and raises the returns to each unit of search effort. Additionally, labor market tightness was particularly low when FPUC was implemented, such that decreasing search effort likely had limited effects on unemployment. Our findings hence help explain why prior studies have found no effect of FPUC on unemployment (Bartik et al., 2020; Altonji et al., 2020; Finamor and Scott, 2021; Dube, 2020).

\subsection{The impact of FPUC on welfare}

Our results speak to aspects of the impact of FPUC on welfare that have to do with labor market tightness. Landais et al. (2018b) formalize that the welfare impact of unemployment insurance depends on three elements: first, its impact on labor market tightness; second, the impact of tightness on welfare, and third, the trade-off between consumption smoothing and moral hazard. Our paper provides evidence on the first two. We show that FPUC increased tightness, and that tightness was particularly low at that time. Our results together suggest that FPUC increased welfare by bringing labor market tightness back towards a more efficient level. Intuitively, it strongly decreased the cost of unemployment for job seekers without a commensurate increase in recruitment difficulties for employers. Importantly, this conclusion also holds for the reopening phase (June-July 2020). In this period, one could have expected a clearer negative impact of FPUC on vacancy creation, since economic activity was no longer hindered by lockdown measures. However, we find no evidence of this. One could also have feared labor market tightness to be particularly high during this period, since firms' recruiting was picking up while many unemployed workers were receiving FPUC. We show that labor market tightness was just back to its pre-pandemic level, despite the positive effect of FPUC on tightness. In the absence of FPUC, the counterfactual level of tightness would likely have remained lower than in baseline.

While our analysis focuses on labor market tightness, one should also consider other important elements to determine the welfare impact of FPUC. During the COVID-19 crisis, the sanitary situation made unemployment more desirable than in normal times, to the extent that unemployed workers were less likely to get infected with COVID-19 and infect others (Fang et al., 2020). Moreover, workers appeared to rely heavily on FPUC to sustain their consumption, and FPUC likely boosted employment through a stimulus effect (Ganong et al. 2021) ${ }^{12}$ Overall, these elements all point towards the desirability of high unemployment insurance benefits during this crisis.

\footnotetext{
${ }^{12}$ We don't capture stimulus effects with our identification strategy, as they don't necessarily affect jobs where workers experience the largest increase in potential replacement rates.
} 


\section{Conclusion}

During the COVID-19 crisis, a 10\% increase in unemployment benefits due to the Federal Unemployment Pandemic Assistance (FPUC) led to a 3.6\% decline in Glassdoor job applications. Since the FPUC had no effect on vacancies, its effect on applications led to a commensurate $3.3 \%$ increase in labor market tightness (vacancies/applications). However, despite the negative effect of FPUC on applications, seasonally adjusted aggregate job applications remained fairly stable during the FPUC period. With a $4 \%$ increase in aggregate applications and a steep 26\% decline in job vacancies relative to January-February 2020, seasonally adjusted labor market tightness declined by $31 \%$ during the FPUC period. Even in the top $25 \%$ of labor markets with the highest increase in the level of unemployment benefits, tightness still declined by 19\% during the FPUC period. By decreasing applications, FPUC has thus contributed to lifting up a depressed labor market tightness, likely increasing welfare. In a context of excessive competition for jobs among workers, more generous unemployment insurance reduces wasteful applications and has little effect on employment. Our results can help explain why higher unemployment benefits had no effect on employment after the CARES Act (Bartik et al., 2020; Altonji et al., 2020; Dube, 2020). 


\section{Bibliography}

Altonji J, Contractor Z, Finamor L, Haygood R, Lindenlaub I, Meghir C, O'Dea C, Scott D, Wang L, Washington E. 2020. Employment Effects of Unemployment Insurance Generosity During the Pandemic : 24.

Bartik A, Bertrand M, Lin F, Rothstein J, Unrath M. 2020. Measuring the Labor Market at the Onset of the COVID-19 Crisis. SSRN Electronic Journal ISSN 1556-5068. URL https : //www.ssrn. com/abstract=3633053

Birinci S, Karahan F, Mercan Y, See K. 2021. Labor market policies during an epidemic. Journal of Public Economics 194: 104348. ISSN 0047-2727. URL https://www.sciencedirect.com/science/article/pii/S0047272720302127

Boar C, Mongey S. 2020. Dynamic Trade-offs and Labor Supply Under the CARES Act. Technical Report w27727, National Bureau of Economic Research.

URL https://www . nber .org/papers/w27727

Campello M, Kankanhalli G, Muthukrishnan P. 2020. Corporate Hiring under COVID19: Labor Market Concentration, Downskilling, and Income Inequality. SSRN Scholarly Paper ID 3596655, Social Science Research Network, Rochester, NY.

URL https://papers.ssrn.com/abstract=3596655

Chamberlain A, Zhao D. 2019. Glassdoor Job Market Report Methodology. Technical report, Glassdoor.

URL https : //www .glassdoor . com/research/glassdoor-job-market-report-methodology/

Cheng W, Carlin P, Carroll J, Gupta S, Rojas FL, Montenovo L, Nguyen TD, Schmutte IM, Scrivner O, Simon KI, Wing C, Weinberg B. 2020. Back to Business and (Re)employing Workers? Labor Market Activity During State COVID-19 Reopenings. Working Paper 27419, National Bureau of Economic Research.

URL http://www . nber .org/papers/w27419

Chetty R, Friedman J, Hendren N, Stepner M, Team TOI. 2020. The Economic Impacts of COVID-19: Evidence from a New Public Database Built Using Private Sector Data. Technical Report w27431, National Bureau of Economic Research, Cambridge, MA. URL http://www . nber .org/papers/w27431.pdf

DellaVigna S, Heining J, Schmieder JF, Trenkle S. 2020. Evidence on Job Search Models from a Survey of Unemployed Workers in Germany : 49.

Dingel JI, Neiman B. 2020. How many jobs can be done at home? Journal of Public Economics 189: 104235. ISSN 0047-2727.

URL https://www.sciencedirect.com/science/article/pii/S0047272720300992

Dube A. 2020. The Impact of the Federal Pandemic Unemployment Compensation on Employment: Evidence from the Household Pulse Survey : 7.

Fairlie RW, Couch K, Xu H. 2020. The Impacts of COVID-19 on Minority Unemployment: First Evidence from April 2020 CPS Microdata. Working Paper 27246, National Bureau of Economic Research.

URL http://www.nber.org/papers/w27246 
Fang L, Nie J, Xie Z. 2020. Unemployment Insurance During a Pandemic. SSRN Scholarly Paper ID 3666545, Social Science Research Network, Rochester, NY.

URL https://papers.ssrn.com/abstract=3666545

Finamor L, Scott D. 2021. Labor market trends and unemployment insurance generosity during the pandemic. Economics Letters 199: 109722. ISSN 0165-1765.

URL http://www.sciencedirect.com/science/article/pii/S0165176520304821

Flood S, Warren RJ, King M, Rodgers R. 2020. Integrated Public Use Microdata Series, Current Population Survey: Version 8.0 [dataset].

URL https://doi.org/10.18128/D030.V8.0

Forsythe E, Kahn LB, Lange F, Wiczer D. 2020a. Labor demand in the time of COVID19: Evidence from vacancy postings and UI claims. Journal of Public Economics 189: 104238. ISSN 0047-2727.

URL https://www.sciencedirect.com/science/article/pii/S004727272030102X

Forsythe E, Kahn LB, Lange F, Wiczer D. 2020b. Labor demand in the time of COVID19: Evidence from vacancy postings and UI claims. Journal of Public Economics 189: 104238. ISSN 0047-2727.

URL https://www.sciencedirect.com/science/article/pii/S004727272030102X

Forsythe E, Kahn LB, Lange F, Wiczer DG. 2020c. Searching, Recalls, and Tightness: An Interim Report on the COVID Labor Market. Technical Report w28083, National Bureau of Economic Research.

URL https://www . nber .org/papers/w28083

Fradkin A, Baker S. 2017. The impact of unemployment insurance on job search: Evidence from google search data. Review of Economics and Statistics 99: 756-768. Tex.dateadded: 2018-06-07 15:57:53 +0000 tex.date-modified: 2018-06-07 15:59:49 +0000.

Ganong P, Greig F, Liebeskind M, Noel P, Sullivan DM, Vavra J. 2021. Spending and Job Search Impacts of Expanded Unemployment Benefits: Evidence from Administrative Micro Data : 72 .

Ganong P, Noel P, Vavra J. 2020. US Unemployment Insurance Replacement Rates During the Pandemic. SSRN Scholarly Paper ID 3601492, Social Science Research Network, Rochester, NY.

URL https://papers.ssrn.com/abstract=3601492

Gupta S, Montenovo L, Nguyen TD, Rojas FL, Schmutte IM, Simon KI, Weinberg BA, Wing C. 2020. Effects of Social Distancing Policy on Labor Market Outcomes. Working Paper 27280, National Bureau of Economic Research.

URL http://www . nber .org/papers/w27280

Hensvik L, Le Barbanchon T, Rathelot R. 2020. Job Search during the COVID-19 Crisis. SSRN Scholarly Paper ID 3598126, Social Science Research Network, Rochester, NY. URL https://papers .ssrn . com/abstract=3598126

Karabarbounis M, Pinto S. 2018. What Can We Learn from Online Wage Postings? Evidence from Glassdoor. SSRN Scholarly Paper ID 3322205, Social Science Research Network, Rochester, NY.

URL https: //papers.ssrn. com/abstract=3322205 
Krueger AB, Mueller A. 2010. Job search and unemployment insurance: New evidence from time use data. Journal of Public Economics 94: 298-307. URL http://ideas.repec.org/a/eee/pubeco/v94y2010i3-4p298-307.html

Lalive R, Landais C, Zweimueller J. 2015. Market Externalities of Large Unemployment Insurance Extension Programs. American Economic Review 105(12): 3564-3596.

Landais C, Michaillat P, Saez E. 2018a. A Macroeconomic Approach to Optimal Unemployment Insurance: Applications. American Economic Journal: Economic Policy 10: 182-216. ISSN 1945-7731, 1945-774X.

URL https://pubs . aeaweb.org/doi/10.1257/pol.20160462

Landais C, Michaillat P, Saez E. 2018b. A Macroeconomic Approach to Optimal Unemployment Insurance: Theory. American Economic Journal: Economic Policy 10: 152-181. ISSN 1945-7731.

URL https://www . aeaweb.org/articles?id=10.1257/pol.20150088

Lichter A, Schiprowski A. 2020. Benefit duration, job search behavior and re-employment. CESifo Working Papers Tex.date-added: 2017-12-12 13:36:52 +0000 tex.date-modified: 2020-05-14 14:57:32 +0000.

Marinescu I. 2017. The general equilibrium impacts of unemployment insurance: Evidence from a large online job board. Journal of Public Economics 150: 14-29. ISSN 0047-2727. URL http://www.sciencedirect.com/science/article/pii/S0047272717300348

Marinescu I, Skandalis D. 2021. UNEMPLOYMENT INSURANCE AND JOB SEARCH BEHAVIOR. THE QUARTERLY JOURNAL OF ECONOMICS : 45.

Marinescu IE, Wolthoff R. 2019. Opening the Black Box of the Matching Function: the Power of Words. Journal of Labor Economics ISSN 0734-306X.

URL https://www . journals .uchicago.edu/doi/abs/10.1086/705903

Michaillat P. 2012. Do Matching Frictions Explain Unemployment? Not in Bad Times. American Economic Review 102: 1721-50.

Mitman K, Rabinovich S. 2021. Whether, When and How to Extend Unemployment Benefits: Theory and Application to COVID-19 : 41.

Montenovo L, Jiang X, Rojas FL, Schmutte I, Simon K, Weinberg B, Wing C. 2020. Determinants of Disparities in Covid-19 Job Losses. Technical Report w27132, National Bureau of Economic Research, Cambridge, MA.

URL http://www .nber .org/papers/w27132.pdf

Petrosky-Nadeau N. 2020. Reservation Benefits: Assessing Job Acceptance Impacts of Increased UI Payments. Technical Report 2020-28, Federal Reserve Bank of San Francisco. URL https://www .frbsf .org/economic-research/publications/working-papers/ 2020/28/

Pissarides C. 2000. Equilibrium Unemployment Theory. Cambridge: MIT Press., 2nd ed. edition.

Schmieder JF, von Wachter T. 2016. The Effects of Unemployment Insurance Benefits: New Evidence and Interpretation. Annual Review of Economics 8: 547-581.

URL https://doi .org/10.1146/annurev-economics-080614-115758 


\section{Appendix}

Figure A.1: Descriptive statistics on the state of the labor market when FPUC was voted
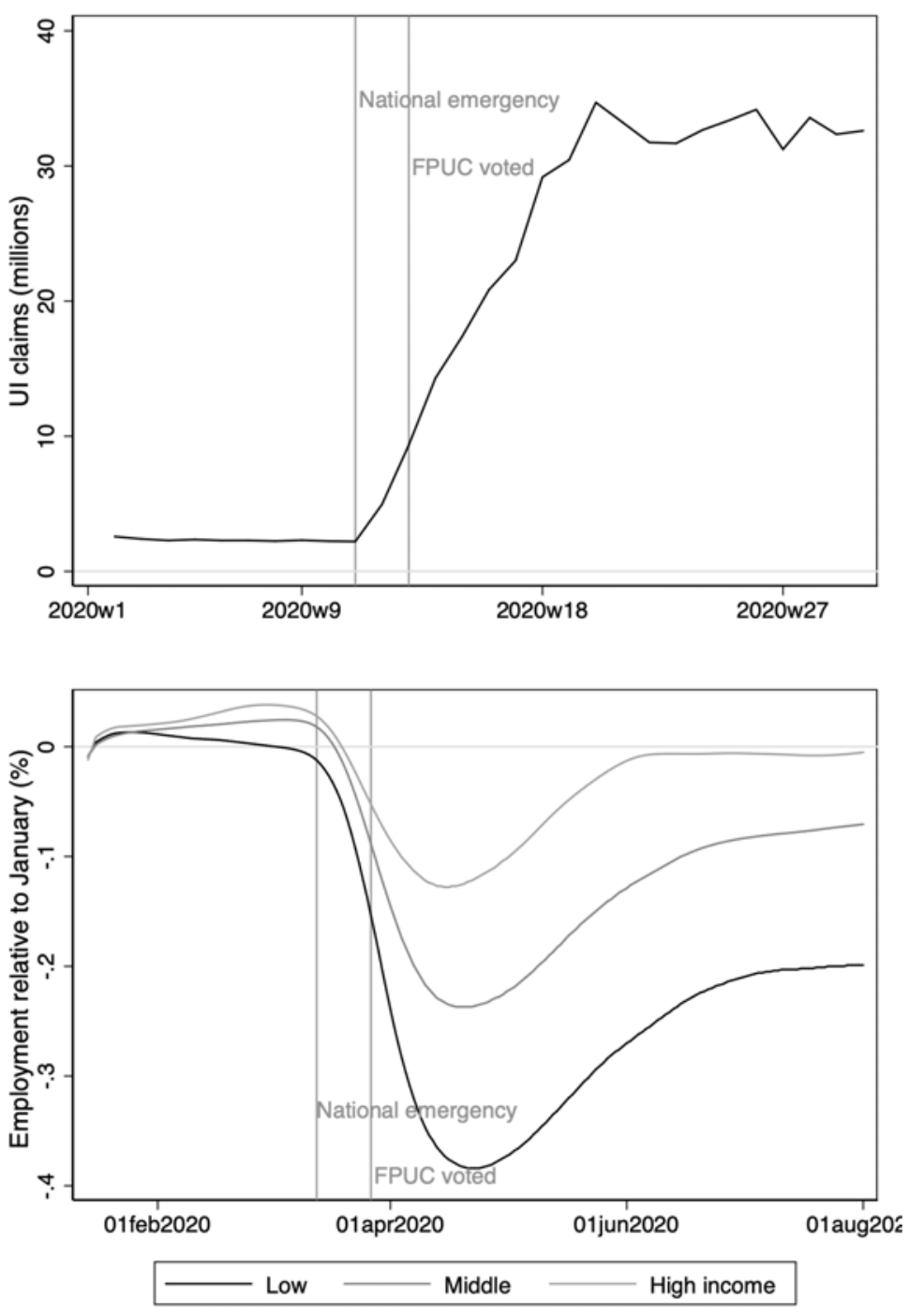

Notes: This Figure shows the evolution of the number of UI claims (new and continuing) in the upper panel. In the lower panel, it shows the evolution of employment rates among workers at different parts of the wage distribution (low wage, middle wage or high wage), relative to their levels in January 2020. The data for the lower panel are described in Chetty et al. (2020), and made publicly available on the website https://tracktherecovery.org. 
Figure A.2: Comparison of the measure of new vacancies from JOLTS and Glassdoor

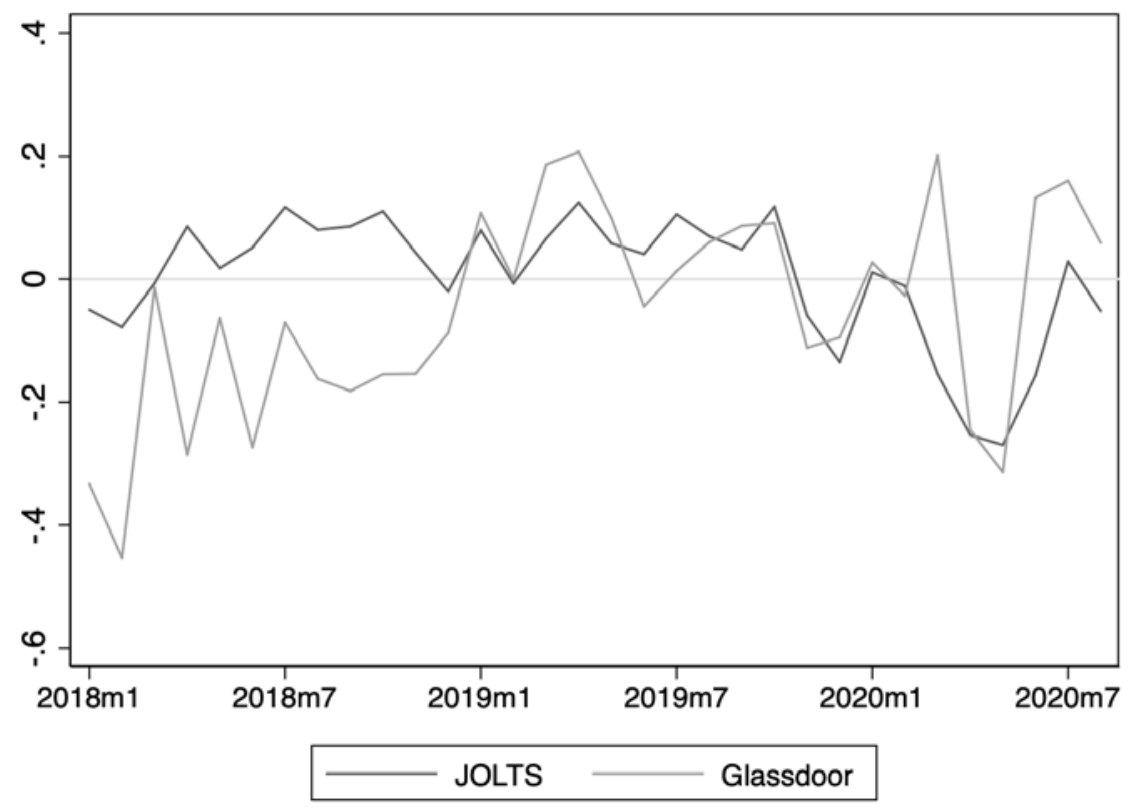

Notes:The Figure presents the variation in the count of new job listing at the monthly level, relative to the average level in January-February 2020. We compare the measure of new vacancies from JOLTS, to the measure from Glassdoor data - which we use in the rest of the paper. For the measure from Glassdoor, we present the weighted sum of job listings, using weights reflecting the size of each Statexindustry $\times$ occupation in the labor force in the CPS. 
Table A.1: Descriptive statistics: Count of applications and job postings on Glassdoor by industry

\begin{tabular}{|c|c|c|c|c|c|}
\hline \multirow{3}{*}{$\begin{array}{l}\text { Data source } \\
\text { Variable }\end{array}$} & \multicolumn{4}{|c|}{ Glassdoor data } & \multirow{3}{*}{$\begin{array}{c}\text { CPS } \\
\text { US labor } \\
\text { force } \\
\%\end{array}$} \\
\hline & \multicolumn{2}{|c|}{$\begin{array}{l}\text { Application count } \\
\text { per week } \times \text { industry }\end{array}$} & \multicolumn{2}{|c|}{$\begin{array}{l}\text { Job posting count } \\
\text { per week } \times \text { industry }\end{array}$} & \\
\hline & Mean & $\%$ & Mean & $\%$ & \\
\hline Agriculture & 15 & 0.00 & 7 & 0.00 & 1.59 \\
\hline Business Service & 81,112 & 17.78 & 84,050 & 13.84 & 12.42 \\
\hline Construction & 4,420 & 0.97 & 3,776 & 0.62 & 7.30 \\
\hline Consumer Service & 6,447 & 1.41 & 8,135 & 1.34 & 4.82 \\
\hline Finance & 49,031 & 10.75 & 39,249 & 6.46 & 6.80 \\
\hline Government & 7,047 & 1.55 & 8,421 & 1.39 & 4.67 \\
\hline Health, Education & 68,506 & 15.02 & 164,691 & 27.12 & 22.51 \\
\hline Information & 105,109 & 23.05 & 65,283 & 10.75 & 1.80 \\
\hline Leisure, hospitality & 30,366 & 6.66 & 72,982 & 12.02 & 9.34 \\
\hline Manufacturing & 46,673 & 10.23 & 33,052 & 5.44 & 9.88 \\
\hline Retail & 43,129 & 9.46 & 69,722 & 11.48 & 12.92 \\
\hline Transportation, warehousing & 14,217 & 3.12 & 57,889 & 9.53 & 5.66 \\
\hline
\end{tabular}

Notes: This Table presents the mean weekly count of applications and new job postings and the proportion of applications and new vacancy postings by industry, in our study sample. In the last column, the Table reports the proportion of US labor force by industry based on the CPS in 2018-2020. 
Table A.2: Descriptive statistics in our study sample

\begin{tabular}{lccccc}
\hline \hline & & & & \\
& Mean & SD & p25 & p50 & p75 \\
& $(1)$ & $(2)$ & $(3)$ & $(4)$ & $(5)$ \\
\hline Count of applications, each week in each local labor market & 82.2 & 204.3 & 12.0 & 26.0 & 70.0 \\
Count of vacancies, each week in each local labor market & 189.6 & 659.1 & 16.0 & 44.0 & 126.0 \\
Tightness (vacancies / applications) & 4.7 & 22.6 & 0.7 & 1.4 & 3.4 \\
Replacement rate without FPUC & 43.6 & 8.4 & 38.2 & 45.4 & 49.2 \\
Replacement rate with FPUC & 146.1 & 47.9 & 107.3 & 143.5 & 173.8 \\
& & & & & \\
\hline \hline
\end{tabular}

Notes: This Table presents descriptive statistics in our study sample. All variables are computed for each calendar week from January 2018 to July 2020, in each local labor market. We use weights reflecting the size of each State $\times$ industry $\times$ occupation in the labor force in the CPS. Note that the distribution of potential replacement rates in local labor markets in this Table is not directly comparable to the distribution of replacement rate in the population of unemployed workers computed in Ganong et al. (2020): the level of observation is different since one observation represents one local labor market in our analysis, while one observation represents one worker who lost their job during the COVID-19 crisis in Ganong et al. (2020). However, we note that these statistics are relatively close, with the first quartile of replacement rate ranging around $103 \%$, the median around 145\%, third quartile around 195\% (Ganong et al., 2020). 
Figure A.3: Variation in the residualized increase in replacement rate in our data

(1) After including State FE

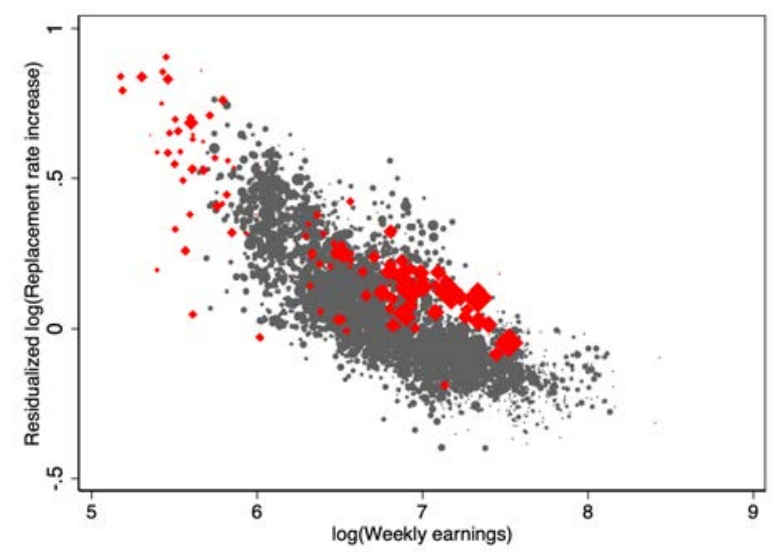

(2) After including State and industry FE

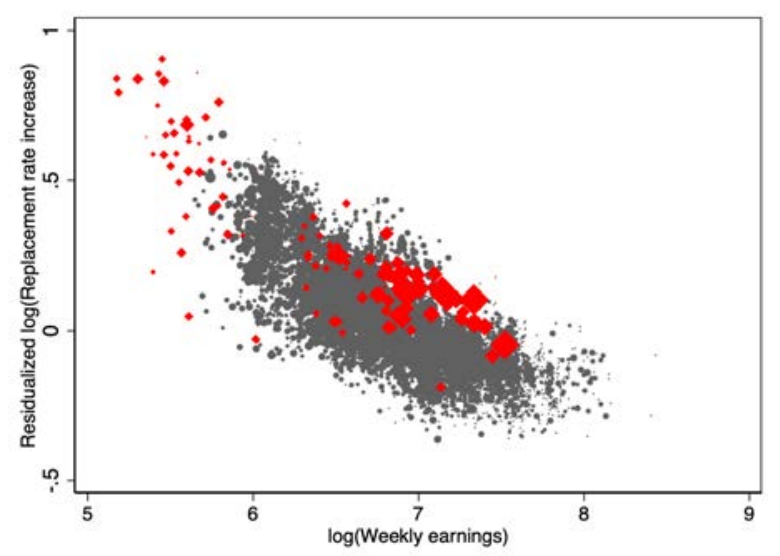

(3) After including State, industry, exposure decile FE

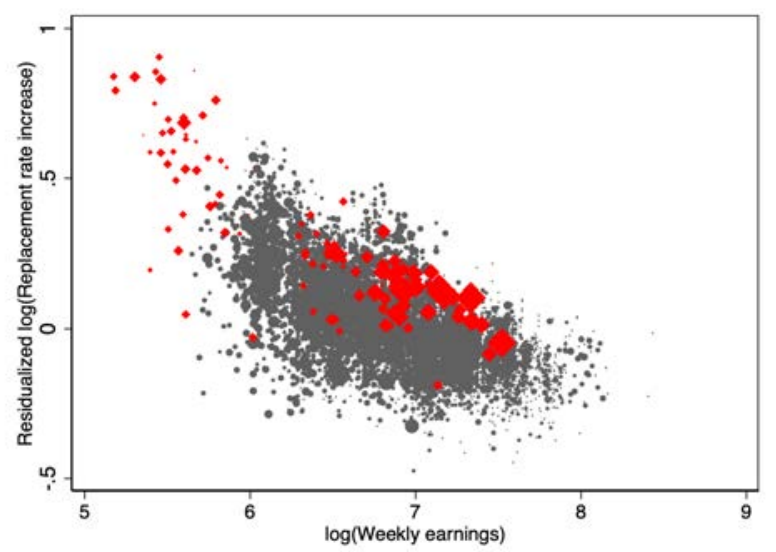

Notes: This Figure illustrates the variation in the residualized increase in replacement rate in our data, which serves to identify the effect of FPUC. The Figure shows that increases in replacement rates are negatively correlated with pre-displacement weekly earnings, and that substantial variation in increase in replacement rate remains even once we take out the portion explained by state, industry, and exposure decile. They are obtained in the cross section of all the local labor market (state by occupation by industry by wage decile) in our study sample. We use weights to reflect the proportion of the labor force in each Statexindustry $\times$ occupation in the CPS, like in the rest of the analysis. As an example, we show in red the observations corresponding to local labor markets for the occupation "salesmen". 
Table A.3: The probability of unemployment in January-March 2020 depending on past earnings, by industry

\begin{tabular}{|c|c|c|c|}
\hline & \multicolumn{3}{|c|}{ Pba Unemployed } \\
\hline & $(1)$ & $(2)$ & $(3)$ \\
\hline $\ln$ (prior earnings) & $\begin{array}{c}-0.372^{* * *} \\
(0.024)\end{array}$ & & \\
\hline Agriculture $\times \ln$ (prior earnings) & & $\begin{array}{c}-0.525^{* * *} \\
(0.198)\end{array}$ & $\begin{array}{c}-0.541^{* * *} \\
(0.208)\end{array}$ \\
\hline Mining $\times \ln ($ prior earnings $)$ & & $\begin{array}{l}-0.061 \\
(0.393)\end{array}$ & $\begin{array}{l}-0.047 \\
(0.395)\end{array}$ \\
\hline Construction $\times \ln ($ prior earnings $)$ & & $\begin{array}{l}-0.096 \\
(0.088)\end{array}$ & $\begin{array}{c}-0.097 \\
(0.089)\end{array}$ \\
\hline Manufacturing $\times \ln ($ prior earnings $)$ & & $\begin{array}{c}-0.531^{* * *} \\
(0.097)\end{array}$ & $\begin{array}{c}-0.553^{* * *} \\
(0.096)\end{array}$ \\
\hline Retail $\times \ln ($ prior earnings $)$ & & $\begin{array}{c}-0.433^{* * *} \\
(0.081)\end{array}$ & $\begin{array}{c}-0.449^{* * *} \\
(0.081)\end{array}$ \\
\hline Transportation $\times \ln ($ prior earnings $)$ & & $\begin{array}{c}-0.521^{* * *} \\
(0.111)\end{array}$ & $\begin{array}{c}-0.539^{* * *} \\
(0.110)\end{array}$ \\
\hline Information $\times \ln ($ prior earnings $)$ & & $\begin{array}{c}-0.248^{*} \\
(0.130)\end{array}$ & $\begin{array}{c}-0.236^{*} \\
(0.134)\end{array}$ \\
\hline Finance $\times \ln ($ prior earnings $)$ & & $\begin{array}{c}-0.266^{* * *} \\
(0.057)\end{array}$ & $\begin{array}{c}-0.277^{* * *} \\
(0.059)\end{array}$ \\
\hline Business services $\times \ln ($ prior earnings $)$ & & $\begin{array}{c}-0.388^{* * *} \\
(0.066)\end{array}$ & $\begin{array}{c}-0.403^{* * *} \\
(0.067)\end{array}$ \\
\hline Education $\&$ health $\times \ln ($ prior earnings $)$ & & $\begin{array}{c}-0.360^{* * *} \\
(0.043)\end{array}$ & $\begin{array}{c}-0.370^{* * *} \\
(0.045)\end{array}$ \\
\hline Leisure $\&$ hospitality $\times \ln ($ prior earnings $)$ & & $\begin{array}{c}-0.262^{* * *} \\
(0.087)\end{array}$ & $\begin{array}{c}-0.264^{* * *} \\
(0.088)\end{array}$ \\
\hline Consumer services $\times \ln ($ prior earnings $)$ & & $\begin{array}{c}-0.657^{* * *} \\
(0.132)\end{array}$ & $\begin{array}{c}-0.663^{* * *} \\
(0.137)\end{array}$ \\
\hline Government $\times \ln ($ prior earnings $)$ & & $\begin{array}{c}-0.603^{* * *} \\
(0.136)\end{array}$ & $\begin{array}{c}-0.575^{* * *} \\
(0.137)\end{array}$ \\
\hline Industry FE & - & $\checkmark$ & $\checkmark$ \\
\hline State FE & - & - & $\checkmark$ \\
\hline No. of Obs & 54,023 & 54,017 & 54,017 \\
\hline
\end{tabular}

Notes: This table reports the estimates from the logit regressions of a dummy for unemployment on local labor market characteristics: prior earnings, two-digit industries and states. The information on workers' unemployment status, industry, and state come from the monthly CPS data for January-March 2020, and information on their prior earnings come from the Outgoing Rotation Group data for 2019. The two datasets are matched at the individual level. We use individual survey weights from the CPS 2020. Note that as we use the information on earnings from ORG 2019, we could also have computed alternative weights accounting for the composition of respondents in ORG 2019 and correcting for missing earnings values. We use the standard survey weights for replicability, but we checked that this does not affect our results. Robust standard errors in parenthesis $\left(* \mathrm{p}<0.10,{ }^{* *} \mathrm{p}<0.05,{ }^{* * *} \mathrm{p}<0.010\right)$. 
Table A.4: Additional results on the impact of FPUC on vacancies and tightness

\begin{tabular}{|c|c|c|c|c|c|c|c|c|}
\hline & \multicolumn{4}{|c|}{ Vacancies (ln) } & \multicolumn{4}{|c|}{ Tightness (ln) } \\
\hline \multirow{3}{*}{$\ln \left(\frac{\operatorname{Re} p_{F P U C}}{R e p}\right) \times$ FPUC period, March } & $(1)$ & $(2)$ & (3) & (4) & $(5)$ & (6) & $(7)$ & (8) \\
\hline & -0.123 & & & & 0.021 & & & \\
\hline & $(0.075)$ & & & & $(0.084)$ & & & \\
\hline \multirow{2}{*}{$\ln \left(\frac{\operatorname{Re} p_{F P U C}}{R e p}\right) \times$ FPUC period, April } & $-0.247^{* *}$ & & & & 0.138 & & & \\
\hline & $(0.115)$ & & & & $(0.133)$ & & & \\
\hline \multirow{2}{*}{$\ln \left(\frac{\operatorname{Re} p_{F P U C}}{\operatorname{Rep}}\right) \times \mathrm{FPUC}$ period, May } & -0.011 & & & & $0.425 * * *$ & & & \\
\hline & $(0.069)$ & & & & $(0.106)$ & & & \\
\hline \multirow[t]{2}{*}{$\ln \left(\frac{\operatorname{Rep} F P U C}{R e p}\right) \times$ FPUC period, June } & 0.026 & & & & $0.421^{* * *}$ & & & \\
\hline & $(0.087)$ & & & & $(0.133)$ & & & \\
\hline \multirow{2}{*}{$\ln \left(\frac{\operatorname{Rep} p_{F P U C}}{R e p}\right) \times$ FPUC period, July } & 0.111 & & & & $0.437 * * *$ & & & \\
\hline & $(0.092)$ & & & & $(0.132)$ & & & \\
\hline \multirow{2}{*}{$\ln \left(\frac{\operatorname{Re} p_{F P U C}}{\operatorname{Rep}}\right) \times$ FPUC period $\times$ Lockdown } & & -0.109 & & & & $0.246^{* *}$ & & \\
\hline & & $(0.066)$ & & & & $(0.094)$ & & \\
\hline \multirow{2}{*}{$\ln \left(\frac{\operatorname{Re} p_{F P U C}}{R e p}\right) \times$ FPUC period $\times$ Open } & & 0.063 & & & & $0.430^{* * *}$ & & \\
\hline & & $(0.084)$ & & & & $(0.126)$ & & \\
\hline \multirow[t]{2}{*}{$\ln \left(\frac{\operatorname{Rep} p_{F P U C}}{\operatorname{Rep}}\right) \times \mathrm{FPUC}$ period $\times$ Telework } & & & 0.079 & & & & $0.461^{* * *}$ & \\
\hline & & & $(0.098)$ & & & & $(0.153)$ & \\
\hline \multirow{2}{*}{$\ln \left(\frac{\operatorname{Rep} p_{F P U C}}{R e p}\right) \times$ FPUC period $\times$ Not telework } & & & -0.066 & & & & $0.245^{* *}$ & \\
\hline & & & $(0.077)$ & & & & $(0.114)$ & \\
\hline \multirow[t]{2}{*}{ FPUC period $\times$ Telework } & & & -0.096 & & & & -0.227 & \\
\hline & & & $(0.083)$ & & & & $(0.150)$ & \\
\hline \multirow{2}{*}{$\ln \left(\frac{\operatorname{Re} p_{F P U C}}{R e p}\right) \times$ FPUC period $\times$ High temp layoff } & & & & 0.044 & & & & 0.217 \\
\hline & & & & $(0.114)$ & & & & $(0.139)$ \\
\hline \multirow{2}{*}{$\ln \left(\frac{\operatorname{Re} p_{F P U C}}{R e p}\right) \times$ FPUC period $\times$ Low temp layoff } & & & & -0.148 & & & & $0.267^{* *}$ \\
\hline & & & & $(0.090)$ & & & & $(0.118)$ \\
\hline \multirow[t]{2}{*}{ FPUC period $\times$ High temp layoff } & & & & -0.193 & & & & 0.168 \\
\hline & & & & $(0.171)$ & & & & $(0.179)$ \\
\hline P-Value Test May = July & .047 & & & & .852 & & & \\
\hline P-Value Test Lockdown = Open & & .004 & & & & .008 & & \\
\hline P-Value Test Telework = Not Telework & & & .062 & & & & .116 & \\
\hline P-Value Test High temp layoff = Low temp layoff & & & & .178 & & & & .741 \\
\hline Exposure decile $\times$ Time FE, Industry $\times$ Time FE, State $\times$ Time FE, & $\checkmark$ & $\checkmark$ & $\checkmark$ & $\checkmark$ & $\checkmark$ & $\checkmark$ & $\checkmark$ & $\checkmark$ \\
\hline Labor market $\times$ Week of year FE & $\checkmark$ & $\checkmark$ & $\checkmark$ & $\checkmark$ & $\checkmark$ & $\checkmark$ & $\checkmark$ & $\checkmark$ \\
\hline No. of Obs & $1,523,252$ & $1,523,252$ & $1,496,988$ & $1,523,252$ & $1,523,252$ & $1,523,252$ & $1,496,988$ & $1,523,252$ \\
\hline
\end{tabular}

Notes: This Table reports the estimates from the regression of logged vacancies and tightness on various independent variables, in a panel at the calendar week and local labor market level-where local labor markets are defined as as the interaction of state, 2-digit occupations and 2-digit industries and wage deciles. We use weights to reflect the proportion of the labor force in each State $\times$ industry $\times$ occupation in the CPS. Robust standard errors clustered at the state level are in parenthesis $\left({ }^{*} \mathrm{p}<0.10,{ }^{* *} \mathrm{p}<0.05,{ }^{* * *} \mathrm{p}<0.010\right)$. 
Figure A.4: The impact of FPUC on applications week by week

(1) No additional controls

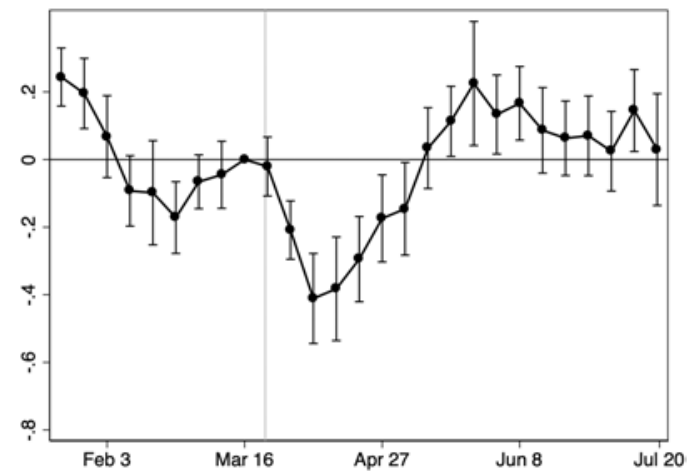

(3) Labor Market $\times$ week-of-year + State $\times$ time FE

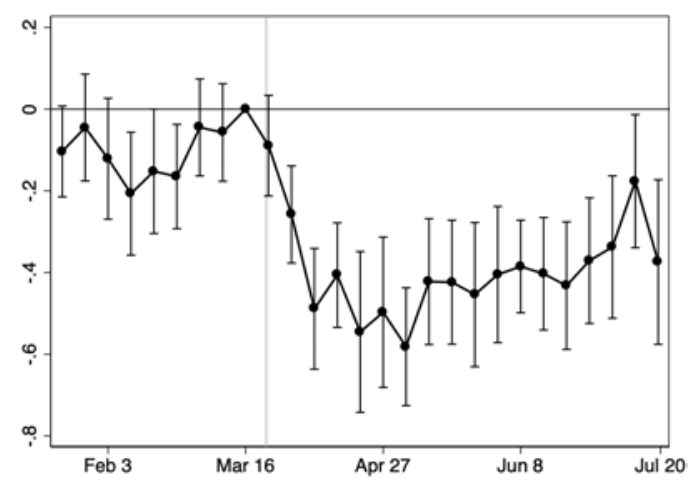

(5) Labor Market $\times$ week-of-year + State $\times$ time FE

+ Exposure decile $\times$ time FE

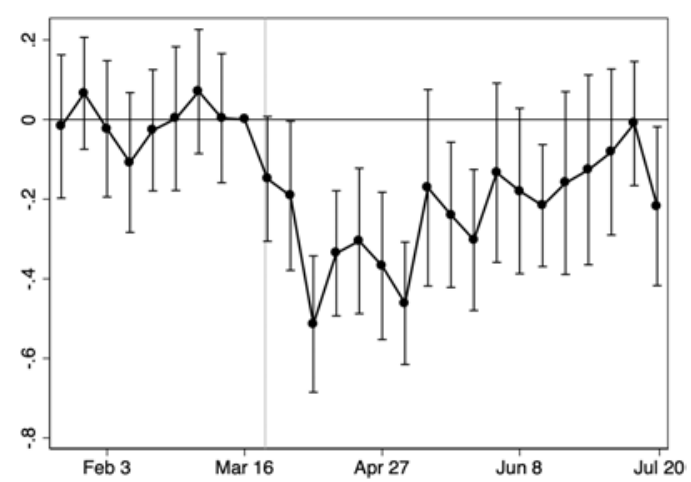

(2) Labor Market × week-of-year FE

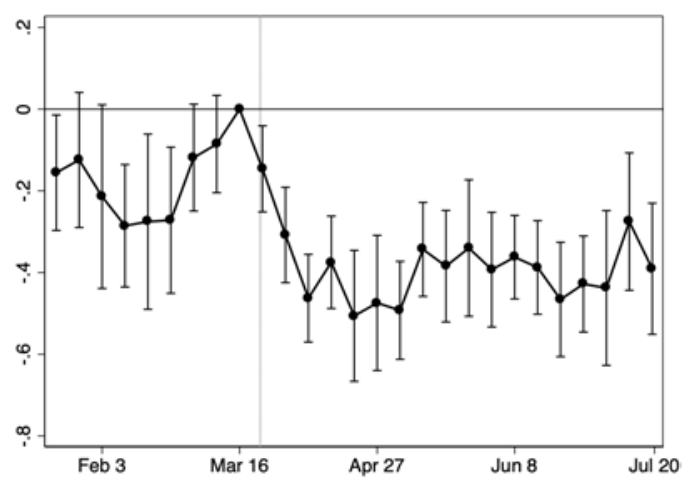

(4) Labor Market $\times$ week-of-year + State $\times$ time + Industry $\times$ time FE

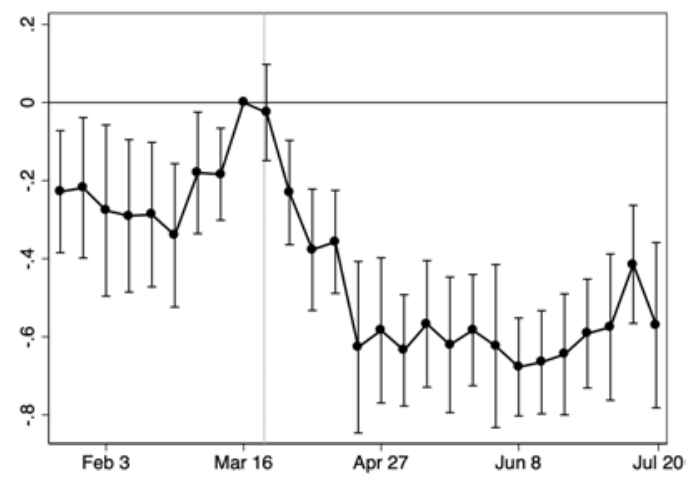

(6) Labor Market $\times$ week-of-year + State $\times$ time + Industry $\times$ time FE + Exposure decile $\times$ time FE

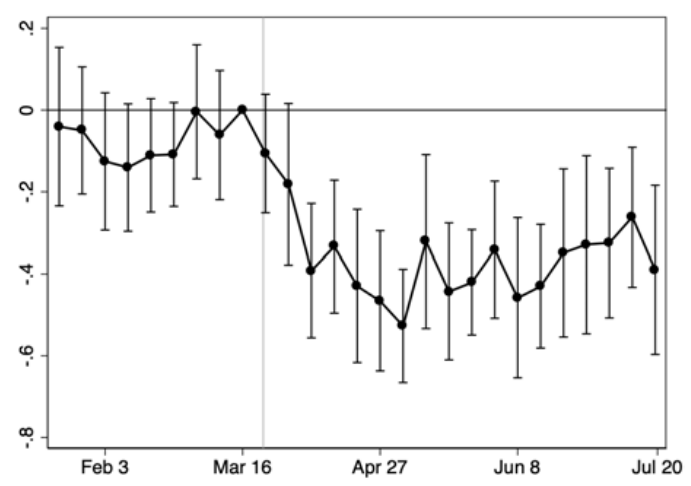

Notes: This Figure reports the estimates from regressions of logged count of applications on the interaction of each week around the enactment of the FPUC and the potential increase in UI generosity $\ln \left(\frac{R e p_{F P U C}}{R e p}\right)$. We use a panel at the calendar week and local labor market level -where local labor markets are defined as as the interaction of state, 2-digit occupations and 2-digit industries and wage deciles. All models include calendar week and local labor market fixed effects. We also add various controls in different panels. We use weights to reflect the proportion of the labor force in each State $\times$ industry $\times$ occupation in the CPS. Thin lines denote $95 \%$ confidence intervals, based on robust SE clustered at the state level. 
Figure A.5: The impact of FPUC on new vacancies week by week

(1) No additional controls

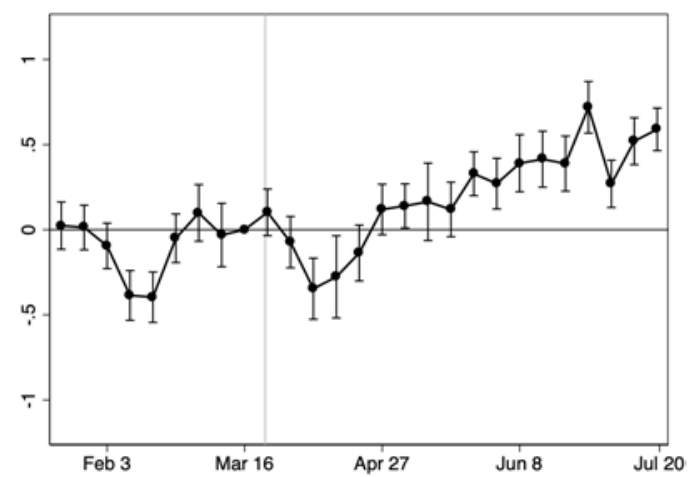

(3) Labor Market $\times$ week-of-year + State $\times$ time FE

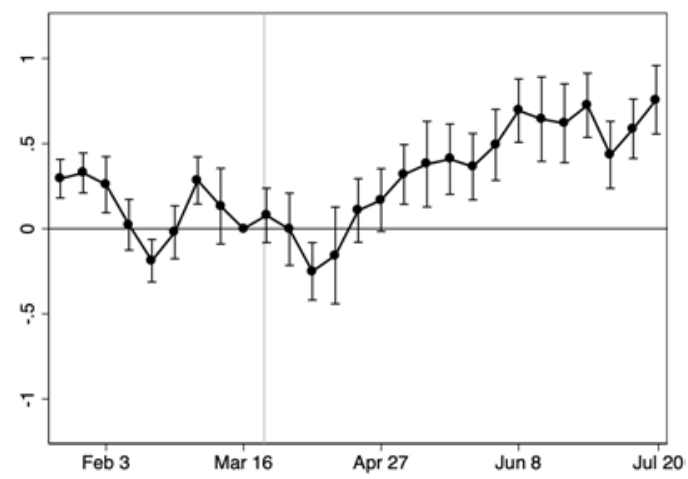

(5) Labor Market $\times$ week-of-year + State $\times$ time FE

+ Exposure decile $\times$ time $\mathrm{FE}$

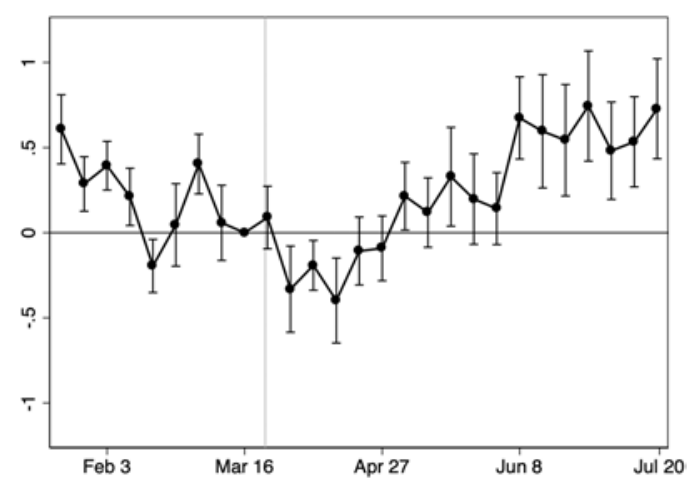

(2) Labor Market × week-of-year FE

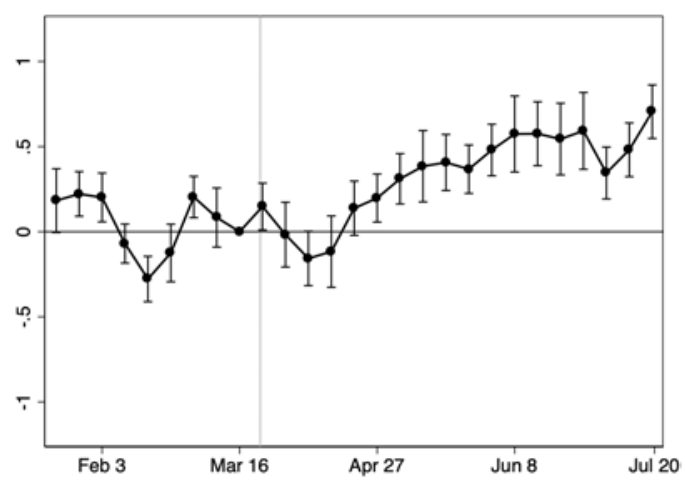

(4) Labor Market $\times$ week-of-year + State $\times$ time + Industry $\times$ time FE

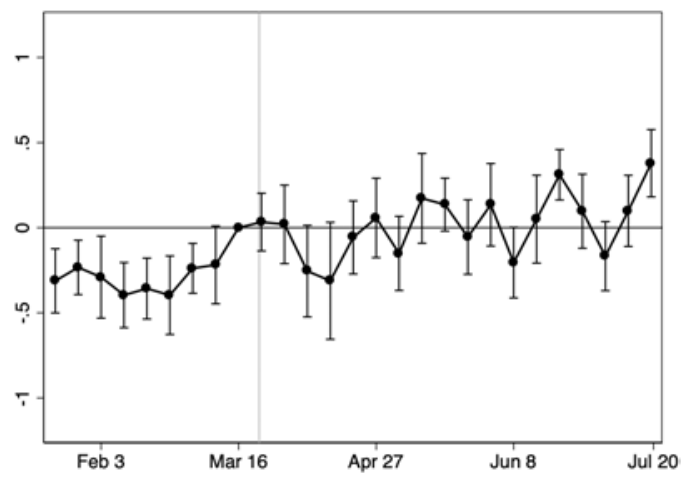

(6) Labor Market $\times$ week-of-year + State $\times$ time + Industry $\times$ time FE + Exposure decile $\times$ time FE

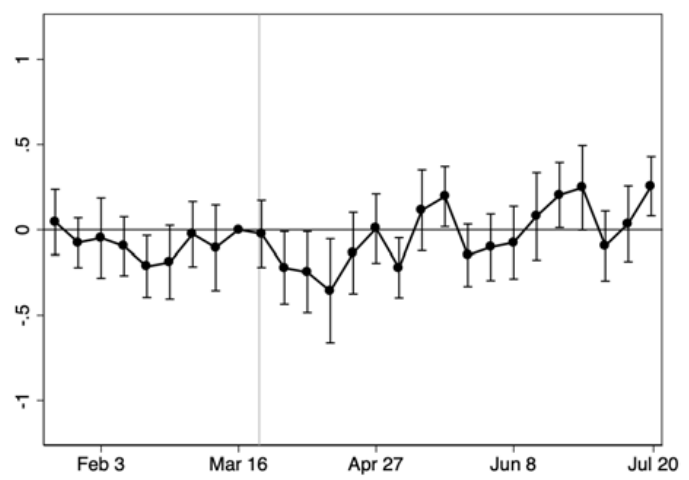

Notes: This Figure reports the estimates from regressions of logged count of new vacancies on the interaction of each week around the enactment of the FPUC and the potential increase in UI generosity $\ln \left(\frac{R e p_{F P U C}}{R e p}\right)$. We use a panel at the calendar week and local labor market level - where local labor markets are defined as as the interaction of state, 2-digit occupations and 2-digit industries and wage deciles. All models include calendar week and local labor market fixed effects. We also add various controls in different panels. We use weights to reflect the proportion of the labor force in each State $\times$ industry $\times$ occupation in the CPS. Thin lines denote $95 \%$ confidence intervals, based on robust SE clustered at the state level. 
Figure A.6: The impact of FPUC on labor market tightness, week by week

(1) No additional controls

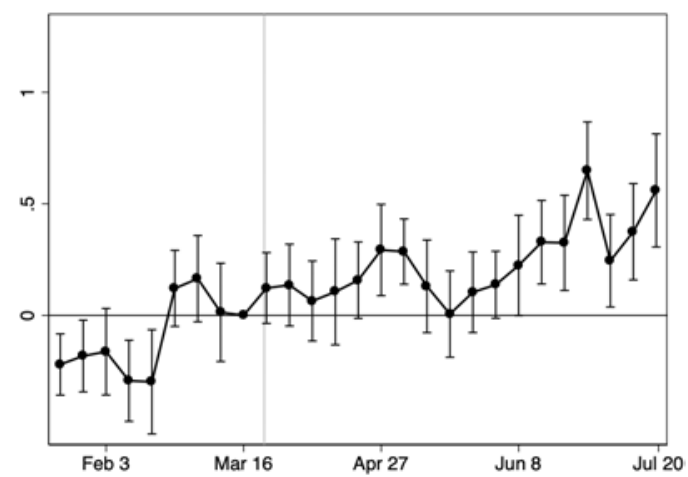

(3) Labor Market $\times$ week-of-year + State $\times$ time FE

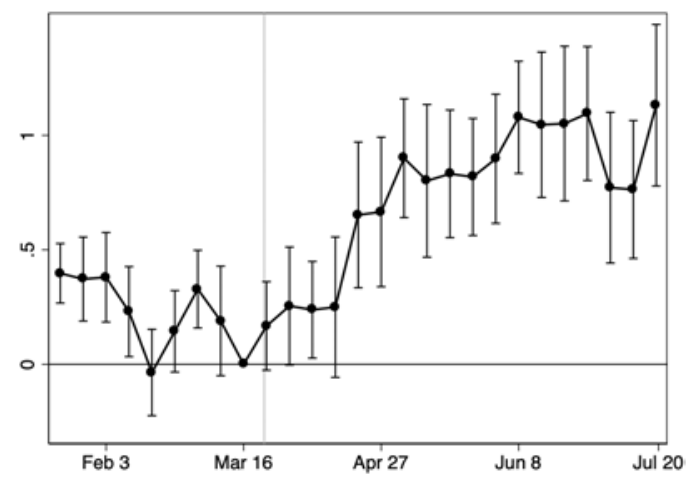

(5) Labor Market × week-of-year + State $\times$ time FE

+ Exposure decile $\times$ time FE

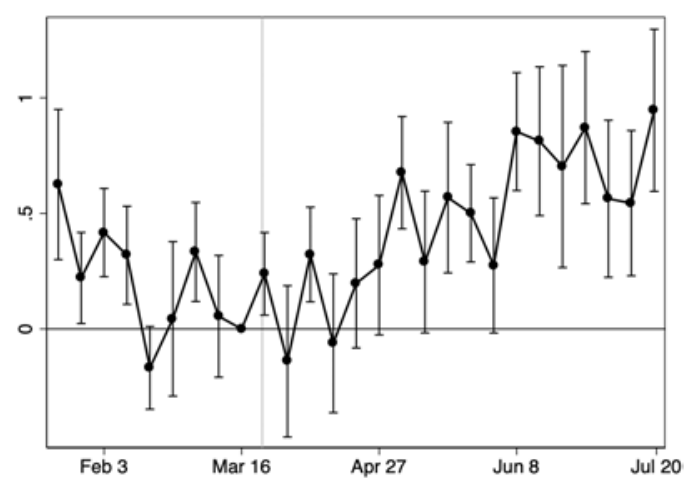

(2) Labor Market × week-of-year FE

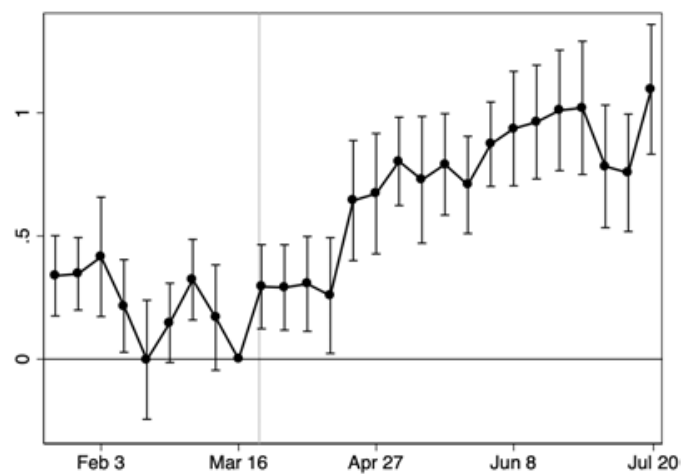

(4) Labor Market $\times$ week-of-year + State $\times$ time + Industry $\times$ time FE

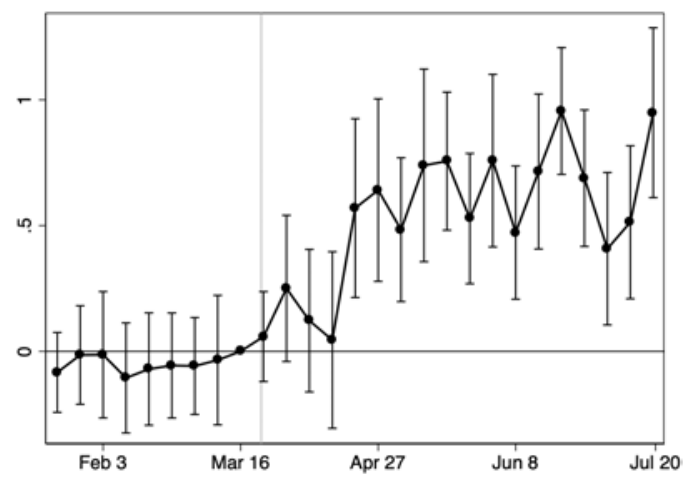

(6) Labor Market $\times$ week-of-year + State $\times$ time + Industry $\times$ time FE + Exposure decile $\times$ time FE

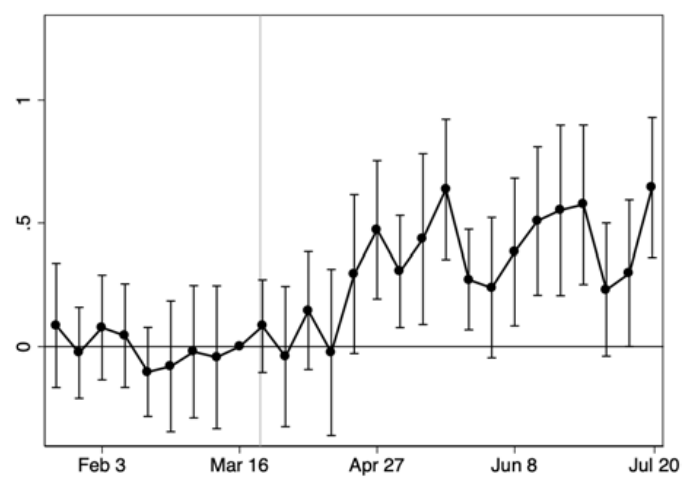

Notes: This Figure reports the estimates from regressions of logged labor market tightness (vacancies/applications) on the interaction of each week around the enactment of the FPUC and the potential increase in UI generosity $\ln \left(\frac{R e p_{F P U C}}{R e p}\right)$. We use a panel at the calendar week and local labor market level - where local labor markets are defined as as the interaction of state, 2-digit occupations and 2-digit industries and wage deciles. All models include calendar week and local labor market fixed effects. We also add various controls in different panels. We use weights to reflect the proportion of the labor force in each State $\times$ industry $\times$ occupation in the CPS. Thin lines denote $95 \%$ confidence intervals, based on robust SE clustered at the state level. 
Table A.5: Robustness checks on the impact of FPUC on applications, vacancies and tightness

\begin{tabular}{|c|c|c|c|c|c|c|}
\hline & $\begin{array}{c}\text { Applications } \\
(\ln )\end{array}$ & $\begin{array}{c}\text { Vacancies } \\
(\ln )\end{array}$ & $\begin{array}{c}\text { Tightness } \\
(\ln )\end{array}$ & $\begin{array}{c}\text { Applications } \\
(\ln )\end{array}$ & $\begin{array}{c}\text { Vacancies } \\
(\ln )\end{array}$ & $\begin{array}{c}\text { Tightness } \\
(\ln )\end{array}$ \\
\hline & $(1)$ & $(2)$ & $(3)$ & $(4)$ & $(5)$ & $(6)$ \\
\hline $\mathrm{Q} 2$ of $\ln \left(\frac{\operatorname{Rep}_{F P U C}}{\operatorname{Rep}}\right) \times \mathrm{FPUC}$ period & $\begin{array}{c}-0.113^{* * *} \\
(0.029)\end{array}$ & $\begin{array}{l}-0.022 \\
(0.046)\end{array}$ & $\begin{array}{c}0.091 \\
(0.058)\end{array}$ & & & \\
\hline $\mathrm{Q} 3$ of $\ln \left(\frac{\operatorname{Re} p_{F P U C}}{\operatorname{Rep}}\right) \times \mathrm{FPUC}$ period & $\begin{array}{c}-0.184^{* * *} \\
(0.037)\end{array}$ & $\begin{array}{c}0.005 \\
(0.042)\end{array}$ & $\begin{array}{c}0.189^{* * *} \\
(0.066)\end{array}$ & & & \\
\hline $\mathrm{Q} 4$ of $\ln \left(\frac{\operatorname{Re} p_{F P U C}}{\operatorname{Rep}}\right) \times \mathrm{FPUC}$ period & $\begin{array}{c}-0.188^{* * *} \\
(0.046)\end{array}$ & $\begin{array}{c}0.007 \\
(0.037)\end{array}$ & $\begin{array}{c}0.195^{* * *} \\
(0.065)\end{array}$ & & & \\
\hline$\left(R e p_{F P U C}-R e p\right) \times$ FPUC period & & & & $\begin{array}{c}-0.218^{* * *} \\
(0.032)\end{array}$ & $\begin{array}{c}-0.013 \\
(0.036)\end{array}$ & $\begin{array}{c}0.205^{* * *} \\
(0.045)\end{array}$ \\
\hline Exposure decile $\times$ Time FE & $\checkmark$ & $\checkmark$ & $\checkmark$ & $\checkmark$ & $\checkmark$ & $\checkmark$ \\
\hline Industry $\times$ Time FE & $\checkmark$ & $\checkmark$ & $\checkmark$ & $\checkmark$ & $\checkmark$ & $\checkmark$ \\
\hline State $\times$ Time FE & $\checkmark$ & $\checkmark$ & $\checkmark$ & $\checkmark$ & $\checkmark$ & $\checkmark$ \\
\hline Labor market $\times$ Week of year FE & $\checkmark$ & $\checkmark$ & $\checkmark$ & $\checkmark$ & $\checkmark$ & $\checkmark$ \\
\hline No. of Obs & $1,523,252$ & $1,523,252$ & $1,523,252$ & $1,523,252$ & $1,523,252$ & $1,523,252$ \\
\hline
\end{tabular}

Notes: This Table reports the estimates from the regression of logged outcomes on various independent variables, in a panel at the calendar week and local labor market level-where local labor markets are defined as as the interaction of state, 2-digit occupations and 2-digit industries and wage deciles. Rep is the replacement rate. We use weights to reflect the proportion of the labor force in each State $\times$ industry $\times$ occupation in the CPS. Robust standard errors clustered at the state level are in parenthesis $\left(* \mathrm{p}<0.10,{ }^{* *} \mathrm{p}<0.05,{ }^{* * *} \mathrm{p}<0.010\right)$. 
Figure A.7: The impact of FPUC on applications, vacancies and tightness in the construction sector, week by week
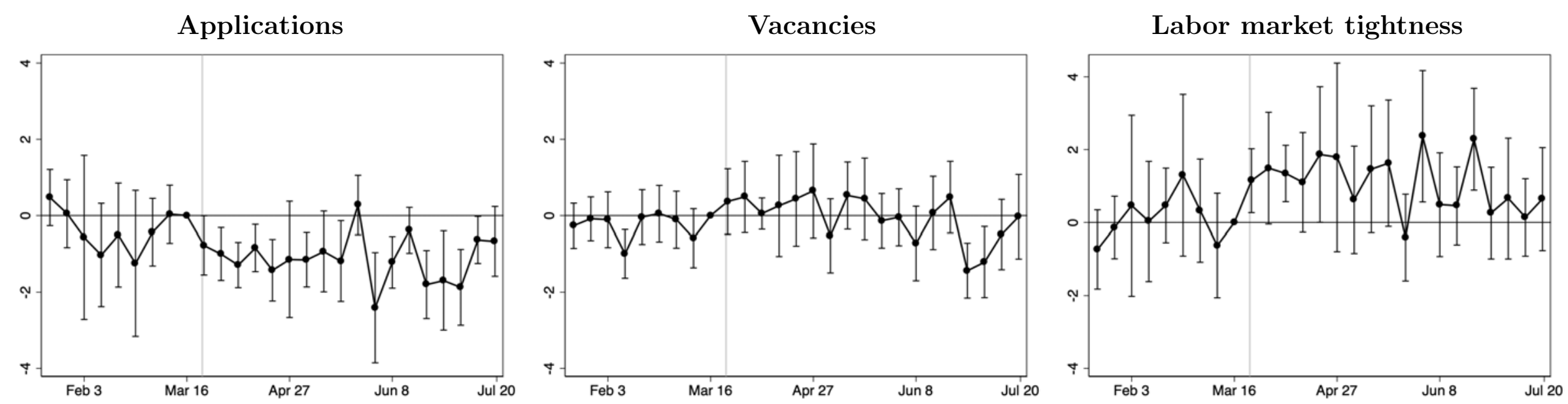

Notes: This Figure reports the estimates from regressions of the logged count of applications, the logged count of vacancies, and the logged labor market tightness (i.e. ratio of vacancies over applications) in the construction sector on the interaction of each week around the enactment of the FPUC and the potential increase in UI generosity $\ln \left(\frac{\operatorname{Re} p_{F P U C}}{R e p}\right)$. The coefficients before the enactment of the FPUC help test our identification assumption. The coefficients after represent the elasticity of the outcome with respect to benefits levels. We use a panel at the calendar week and local labor market level - where local labor markets are defined as as the interaction of state, 2-digit occupations and 2-digit industries and wage deciles. We include calendar week and local labor market fixed effects. We control for seasonality using week-of-year $\times$ local labor market fixed effects. We use weights to reflect the proportion of the labor force in each State $\times$ industry $\times$ occupation in the CPS. Thin lines denote $95 \%$ confidence intervals, based on robust SE clustered at the state level. 
Figure A.8: Changes in applications, vacancies, and labor market tightness relative to Jan-Feb 2020, not seasonally adjusted

Without week of year FE

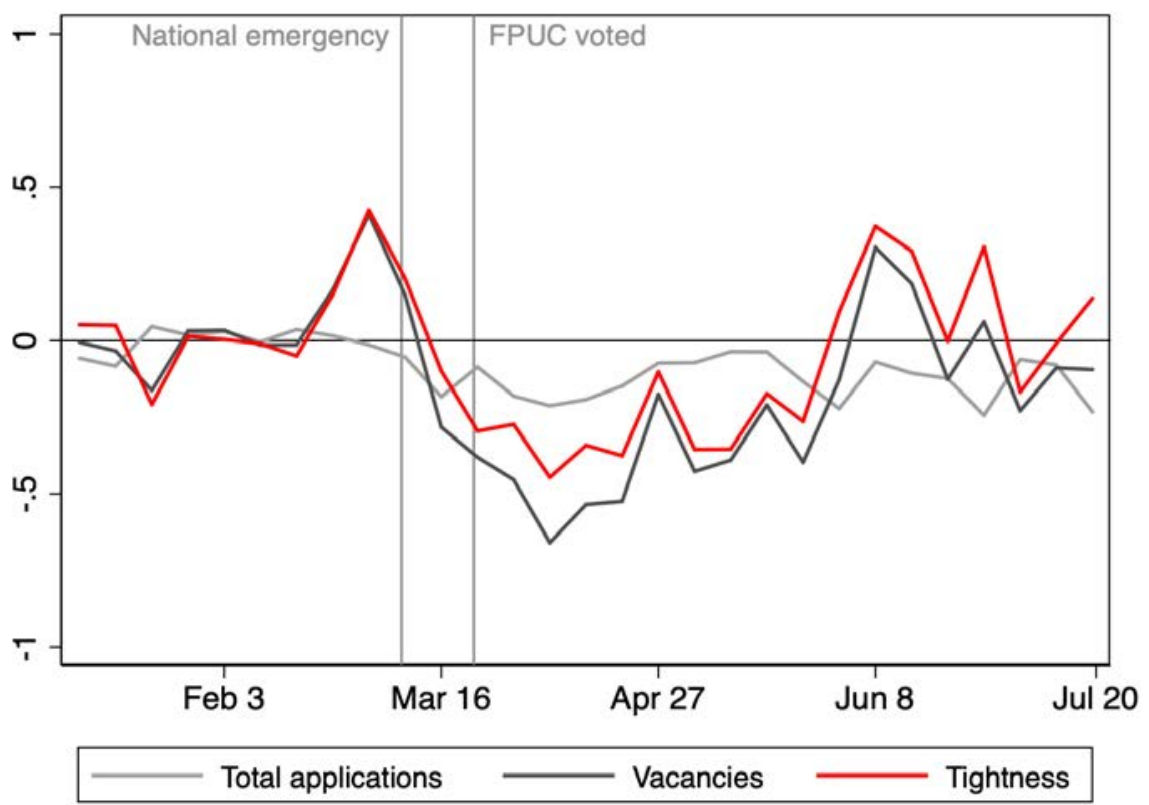

With week of year FE

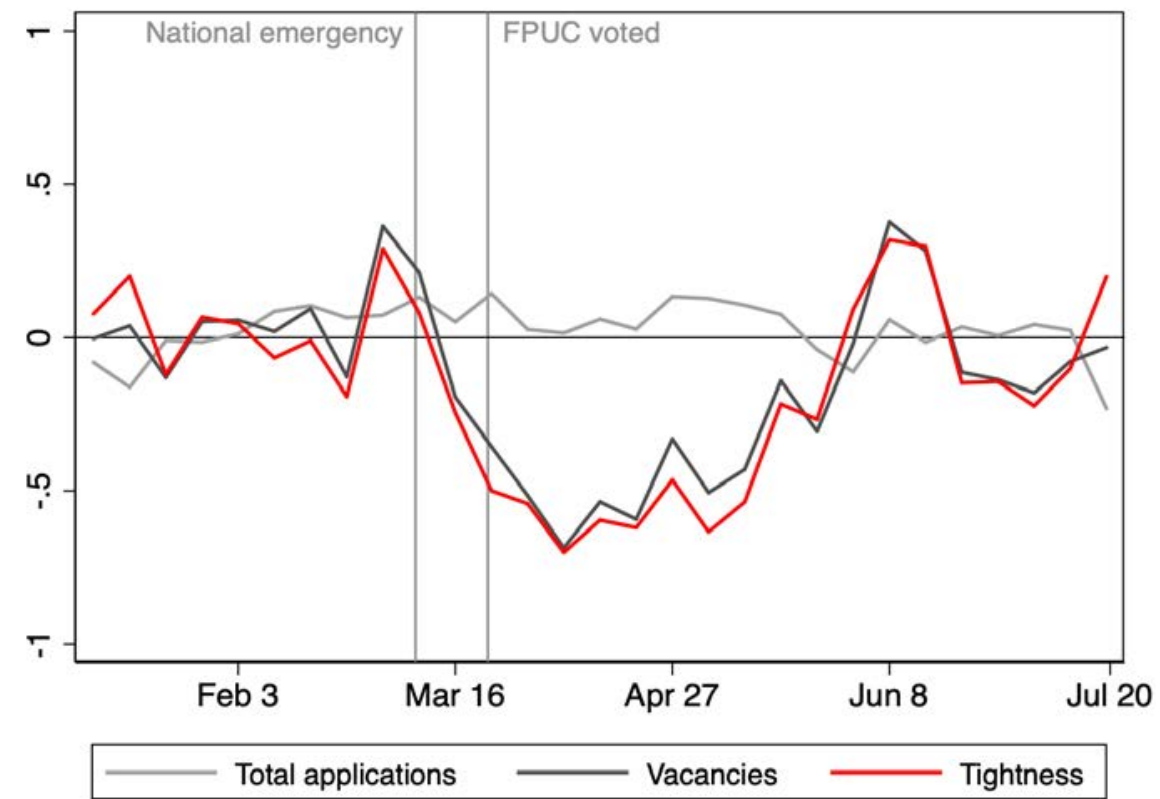

Notes:The Figure presents the changes in tightness (ratio of the weekly count of new posted vacancies over weekly count of applications), relative to their baseline levels in Jan-Feb 2020. We regress the logged tightness on the time coefficients, and then subtract the average of the estimates obtained for the period Jan-Feb 2020, such that each coefficient represents the relative variation with respect to the average level in Jan-Feb 2020. We use weights to reflect the proportion of the labor force in each State $\times$ industry $\times$ occupation in the CPS. 
Figure A.9: Weekly changes in applications, vacancies and tightness relative to Jan-Feb, each year

Applications

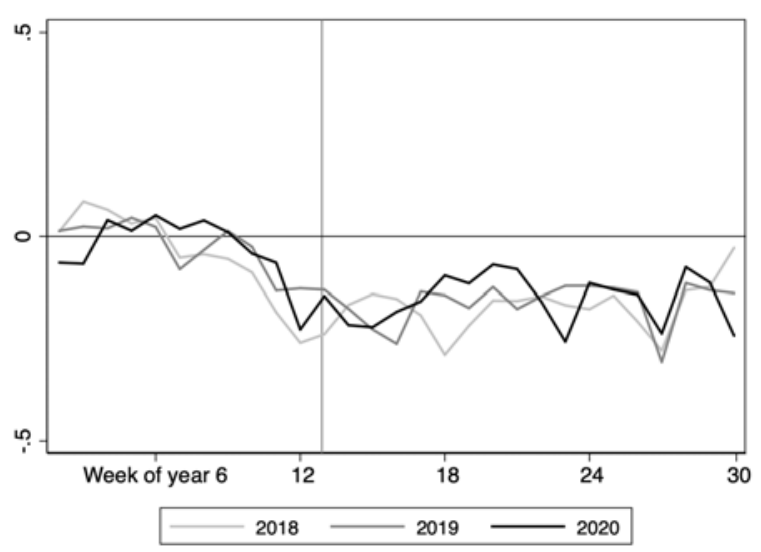

Vacancies

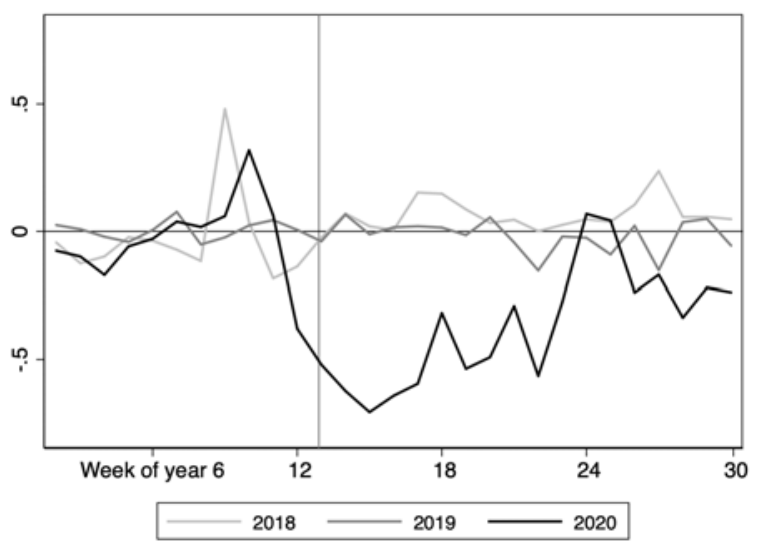

Tightness

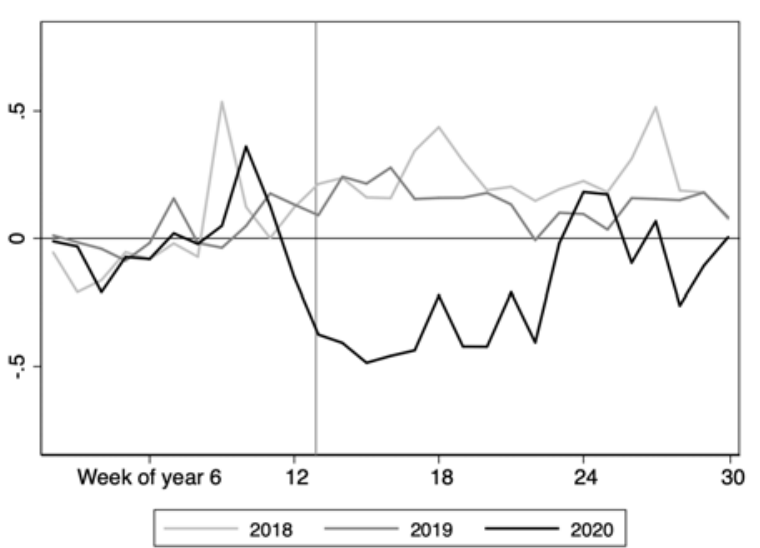

Notes: The Figure presents the weekly changes in the count of applications, of new posted vacancies and of labor market tightness (ratio of the weekly count of new posted vacancies over weekly count of applications), relative to their baseline levels in Jan.-Feb., such that each coefficient represents the relative variation with respect to the average level in Jan.-Feb.. We present them separately for the years 2018,2019 and 2020. We use weights to reflect the proportion of the labor force in each State $\times$ industry $\times$ occupation in the CPS. 
Table A.6: Changes in labor market tightness during the period of the FPUC relative to Jan-Feb 2020, without accounting for seasonal variation

\begin{tabular}{|c|c|c|c|c|c|c|c|}
\hline \multirow{3}{*}{$\begin{array}{l}\text { Sample: } \\
\text { Outcome: }\end{array}$} & \multirow{2}{*}{\multicolumn{3}{|c|}{ All }} & \multicolumn{4}{|c|}{ Potential increase in UI } \\
\hline & & & & Q1 & Q2 & Q3 & Q4 \\
\hline & $\begin{array}{c}\text { Total } \\
\text { Applications }\end{array}$ & Vacancies & Tightness & Tightness & Tightness & Tightness & Tightness \\
\hline & $(1)$ & $(2)$ & $(3)$ & (4) & (5) & (6) & (7) \\
\hline FPUC period & $\begin{array}{c}-0.128^{* * *} \\
(0.021)\end{array}$ & $\begin{array}{c}-0.237^{* * *} \\
(0.024)\end{array}$ & $\begin{array}{c}-0.109^{* * *} \\
(0.024)\end{array}$ & $\begin{array}{c}-0.221^{* * *} \\
(0.022)\end{array}$ & $\begin{array}{c}-0.127^{* * *} \\
(0.032)\end{array}$ & $\begin{array}{c}-0.091^{*} \\
(0.046)\end{array}$ & $\begin{array}{c}0.004 \\
(0.042)\end{array}$ \\
\hline Week of year FE & No & No & No & No & No & No & No \\
\hline No. of Obs & $1,540,598$ & $1,540,598$ & $1,540,598$ & 613,586 & 412,050 & 297,346 & 217,616 \\
\hline FPUC, Mar-May & $\begin{array}{c}-0.117^{* * *} \\
(0.022)\end{array}$ & $\begin{array}{c}-0.415^{* * *} \\
(0.023)\end{array}$ & $\begin{array}{c}-0.298^{* * *} \\
(0.023)\end{array}$ & $\begin{array}{c}-0.356^{* * *} \\
(0.023)\end{array}$ & $\begin{array}{c}-0.325^{* * *} \\
(0.024)\end{array}$ & $\begin{array}{c}-0.310^{* * *} \\
(0.043)\end{array}$ & $\begin{array}{c}-0.201^{* * *} \\
(0.043)\end{array}$ \\
\hline FPUC, Jun-Jul & $\begin{array}{c}-0.142^{* * *} \\
(0.022)\end{array}$ & $\begin{array}{l}-0.014 \\
(0.027)\end{array}$ & $\begin{array}{c}0.128^{* * *} \\
(0.029)\end{array}$ & $\begin{array}{c}-0.052^{* *} \\
(0.026)\end{array}$ & $\begin{array}{c}0.121^{* *} \\
(0.046)\end{array}$ & $\begin{array}{c}0.183^{* * *} \\
(0.056)\end{array}$ & $\begin{array}{c}0.260^{* * *} \\
(0.045)\end{array}$ \\
\hline Week of year FE & No & No & No & No & No & No & No \\
\hline No. of Obs & $1,540,598$ & $1,540,598$ & $1,540,598$ & 613,586 & 412,050 & 297,346 & 217,616 \\
\hline
\end{tabular}

Notes: This Table presents the same estimates as Table 3, except that we do not control for seasonal variation. The Table reports changes in the count of job applications, the count of new posted vacancies, and labor market tightness during the period of the FPUC, relative to their baseline levels in Jan-Feb 2020. In the upper panel, we present estimates for the total period of FPUC, while we divide the FPUC period in two sub-periods in the lower panel. The estimates are obtained by regressing each logged outcome on a dummy for the FPUC period, and a dummy for all calendar weeks outside of the baseline period of January-February 2020 in a panel at the calendar week and local labor market level. The estimates are obtained in the full sample in col (1)-(3), and separately for local labor markets in each quartile of the distribution of potential UI increase in col (4)-(7). We use weights to reflect the proportion of the labor force in each State $\times$ industry $\times$ occupation in the CPS. Robust standard errors clustered at the state level are in parenthesis $\left(* \mathrm{p}<0.10,{ }^{* *} \mathrm{p}<0.05,{ }^{* * *} \mathrm{p}<0.010\right)$. 
Figure A.10: Changes in applications, vacancies and labor market tightness relative to Jan-Feb 2020, by UI increase quartile

First quartile (lowest increase)

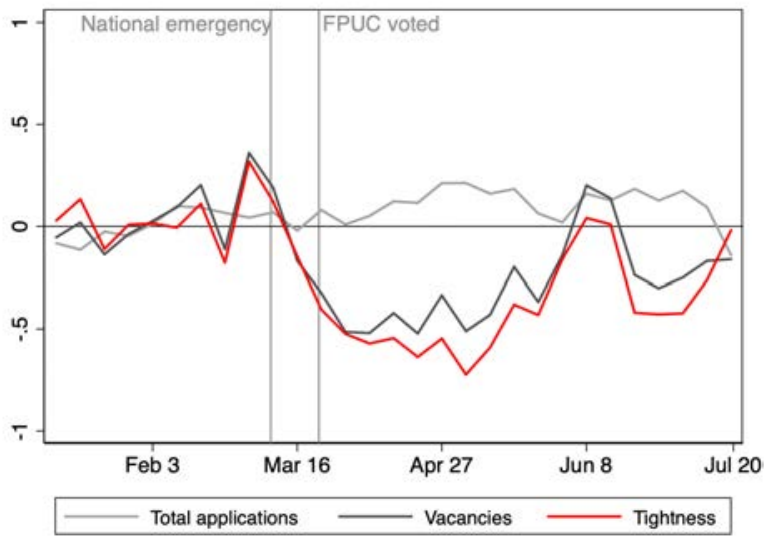

Third quartile

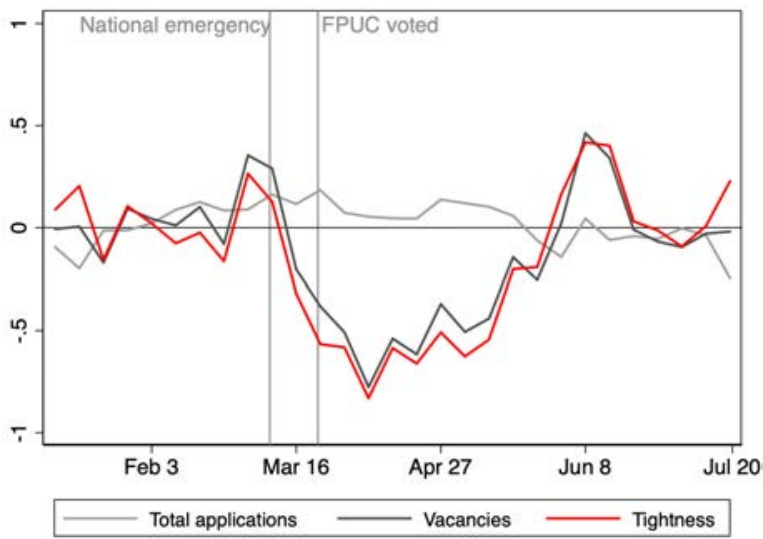

Second quartile

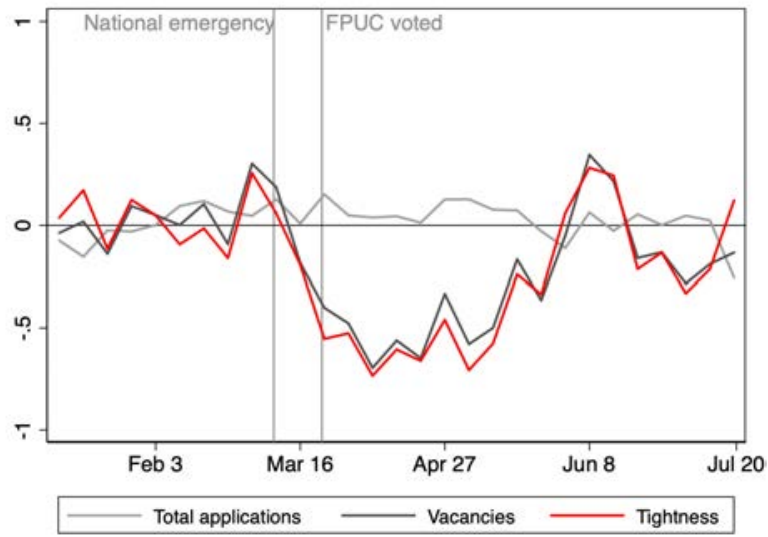

Fourth quartile (largest increase)

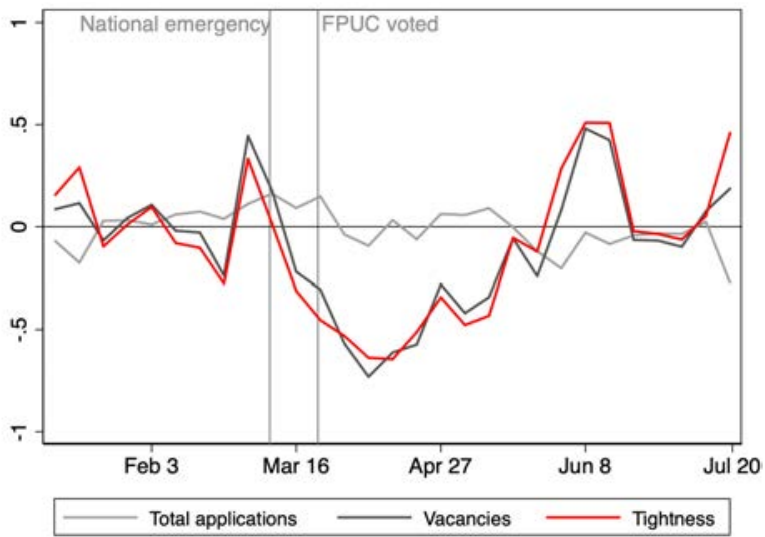

Notes: The Figure presents, for each quartile of the increase in the replacement rate of UI, the seasonally adjusted changes in the total weekly count of applications, the weekly count of new posted vacancies, and labor market tightness (ratio of vacancies over total applications), relative to their baseline levels in Jan-Feb 2020. The Figure is obtained by regressing the logged variables on the calendar week coefficients and week-of-year fixed effects to control for seasonal variation, and then subtracting to each calendar week coefficient the average of estimates for Jan-Feb 2020. We use weights to reflect the proportion of the labor force in each Statexindustry $\times$ occupation in the CPS. 
Figure A.11: The evolution of job applications \& job postings in specific sectors:
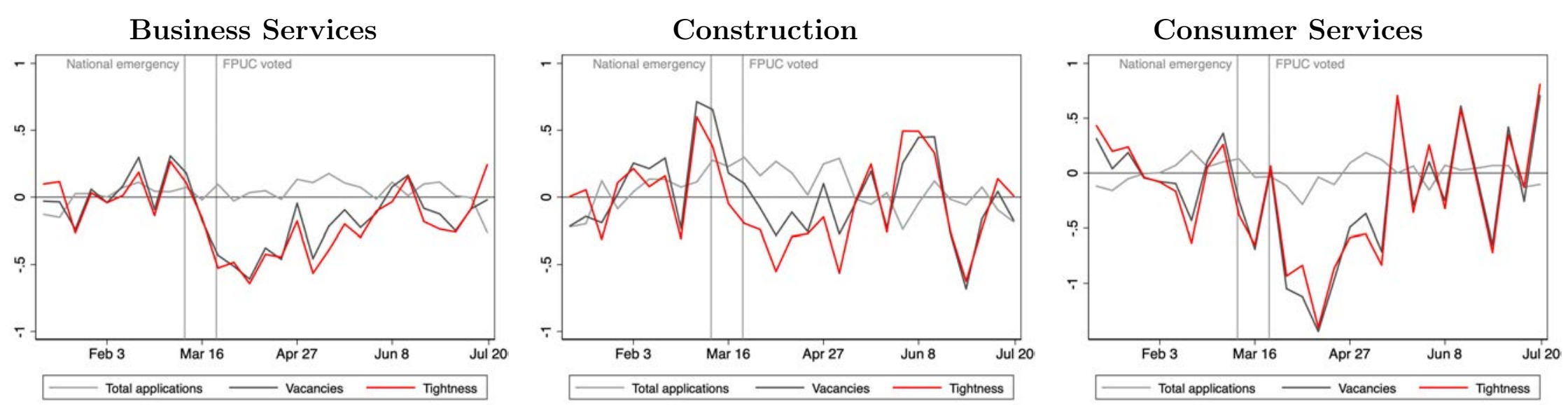

\section{Finance}

$\breve{v}$
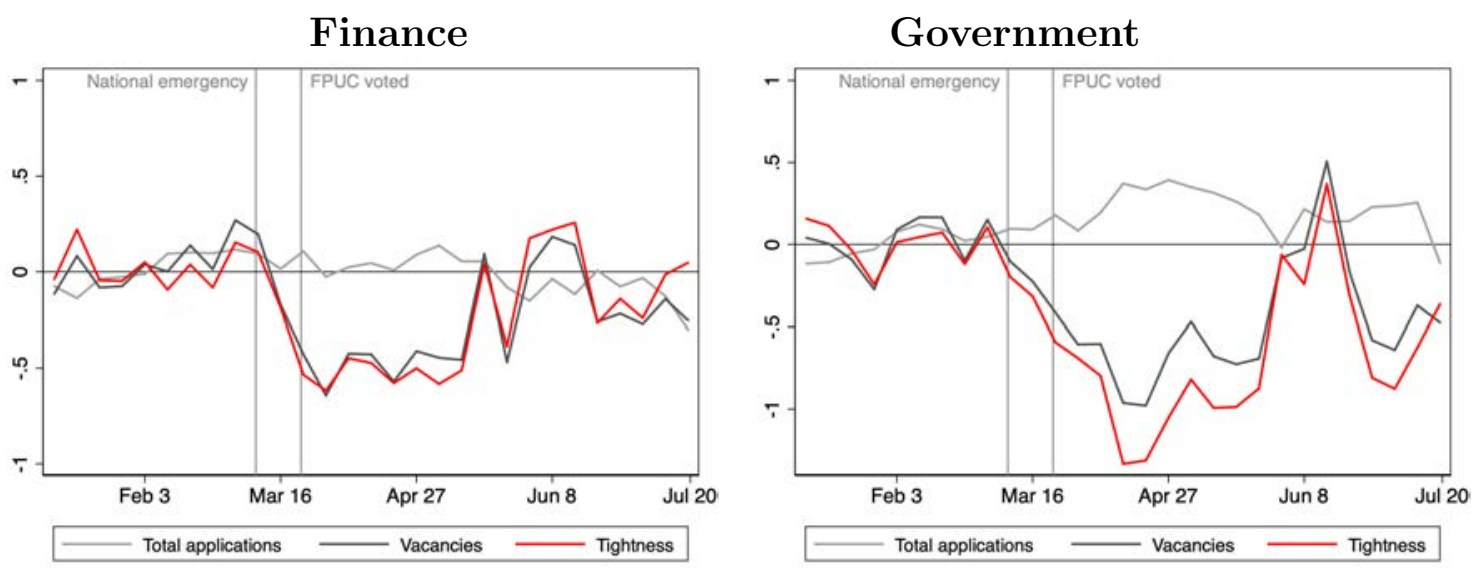

Notes: The Figure presents, fr each industry, the seasonally adjusted changes in the total weekly count of applications, the weekly count of new posted vacancies, and labor market tightness (ratio of vacancies over total applications), relative to their baseline levels in Jan-Feb 2020. The Figure is obtained by regressing the logged variables on the calendar week coefficients and week-of-year fixed effects to control for seasonal variation, and then subtracting to each calendar week coefficient the average of estimates for Jan-Feb 2020. We use weights to reflect the proportion of the labor force in each Statexindustry $\times$ occupation in the CPS. 
Figure A.12: The evolution of job applications \& job postings in specific sectors:

\section{Health, education}

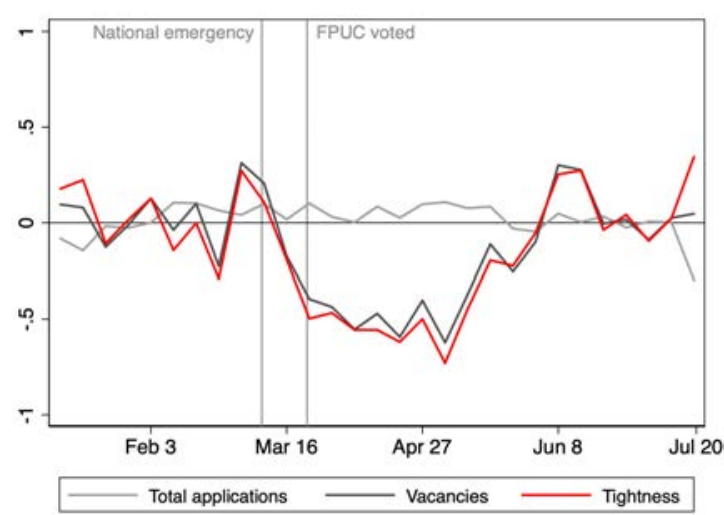

Manufacturing

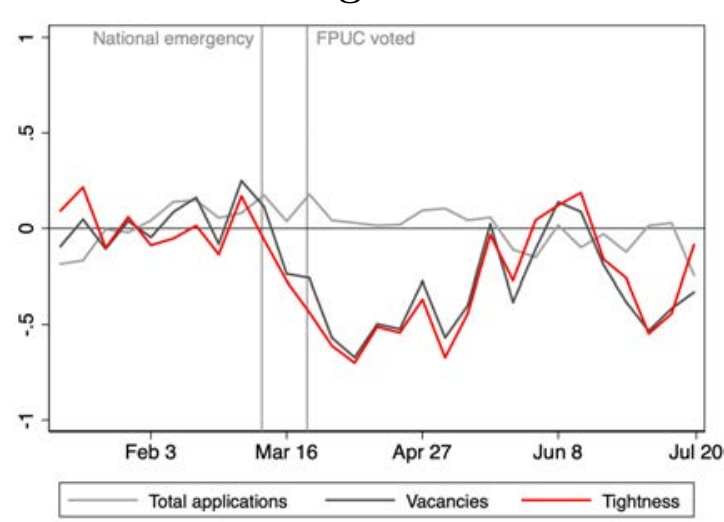

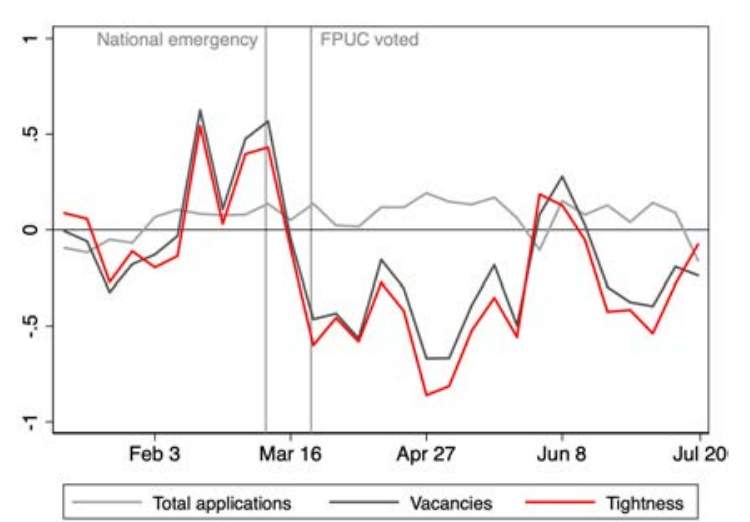

Retail

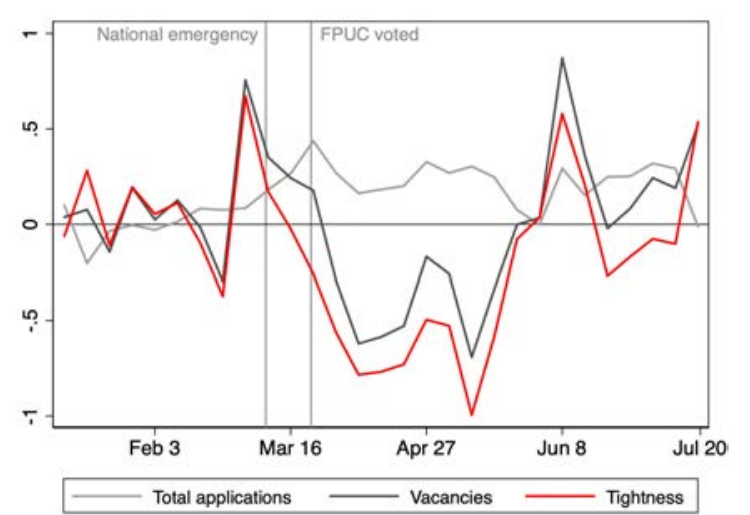

Leisure \& hospitality

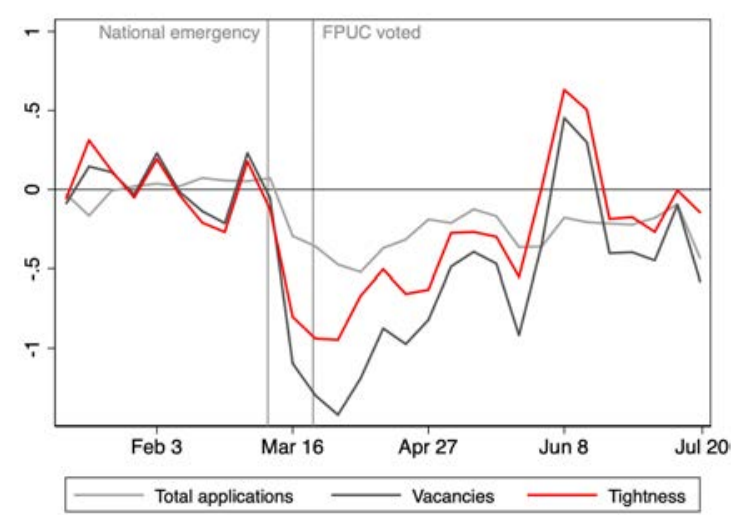

Transport \& logistics

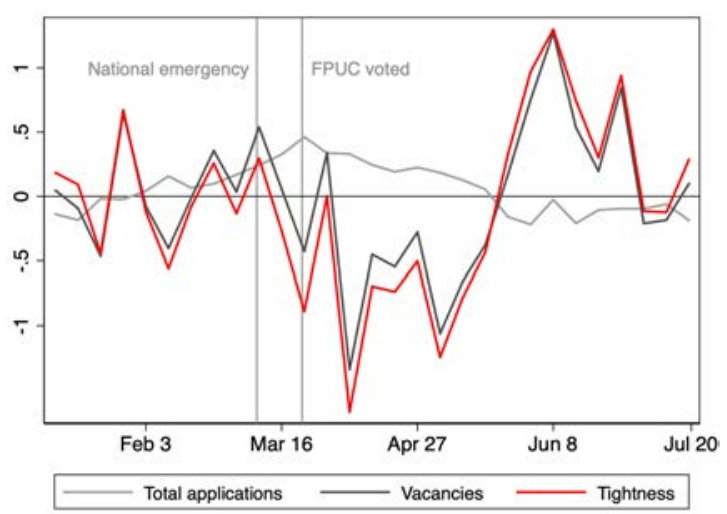

Notes: The Figure presents, for each industry, the seasonally adjusted changes in the total weekly count of applications, the weekly count of new posted vacancies, and labor market tightness (ratio of vacancies over total applications), relative to their baseline levels in Jan-Feb 2020. The Figure is obtained by regressing the logged variables on the calendar week coefficients and week-of-year fixed effects to control for seasonal variation, and then subtracting to each calendar week coefficient the average of estimates for Jan-Feb 2020. We use weights to reflect the proportion of the labor force in each State $\times$ industry $\times$ occupation in the CPS. 